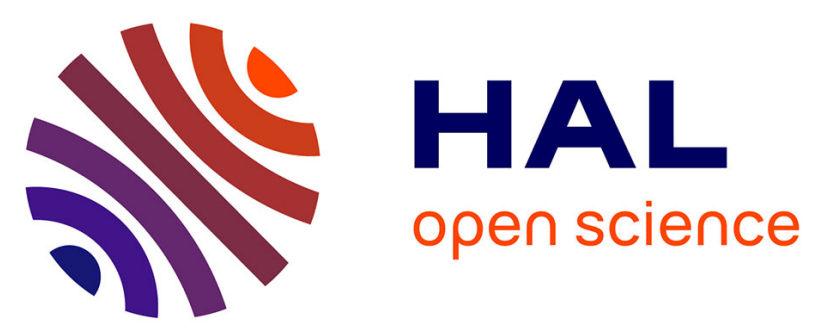

\title{
Using experimental data to reduce the single-building sigma of fragility curves: case study of the BRD tower in Bucharest, Romania
}

Matthieu Perrault, Philippe Gueguen, Alexandru Aldea, Demetriu Sorin

\section{- To cite this version:}

Matthieu Perrault, Philippe Gueguen, Alexandru Aldea, Demetriu Sorin. Using experimental data to reduce the single-building sigma of fragility curves: case study of the BRD tower in Bucharest, Romania. Earthquake Engineering and Engineering Vibration, 2013, 12 (4), pp 643-658. 10.1007/s11803013-0203-z . hal-00934045

\section{HAL Id: hal-00934045 \\ https://hal.science/hal-00934045}

Submitted on 21 Jan 2014

HAL is a multi-disciplinary open access archive for the deposit and dissemination of scientific research documents, whether they are published or not. The documents may come from teaching and research institutions in France or abroad, or from public or private research centers.
L'archive ouverte pluridisciplinaire HAL, est destinée au dépôt et à la diffusion de documents scientifiques de niveau recherche, publiés ou non, émanant des établissements d'enseignement et de recherche français ou étrangers, des laboratoires publics ou privés. 
-Earthquake Engineering and Engineering Vibration, vol. 12, n 4, décembre 2013-

Using experimental data to reduce the single-building sigma of fragility curves: case study of the BRD Tower (Bucharest - Romania)

Matthieu Perrault ${ }^{1}$, Philippe Gueguen ${ }^{1}$, Alexandru Aldea ${ }^{2}$, Sorin Demetriu ${ }^{2}$

1. Institut des Sciences de la Terre, Université Joseph Fourier Grenoble I, CNRS/IFSTTAR

2. Technical University of Civil Engineering, Bucharest, Romania

Sponsor: Vulnérabilité des Ouvrages aux Risques VOR Program, Rhône-Alpes Council.

Acknowledgment: This work was supported by the Rhône-Alpes Regional Council (Programme Vulnerabilité des Ouvrages aux Risques) and the Joseph Fourier Université (Grenoble 1). 


\begin{abstract}
:
The lack of knowledge concerning modelling existing buildings leads to significant variability in fragility curves for single or grouped existing buildings. This paper aims to investigate the uncertainties of fragility curves, with special consideration of the single-building sigma. Experimental data and simplified models are applied to the BRD tower in Bucharest (Romania), a RC building with permanent instrumentation. A 3-step methodology is applied, (1) adjustment of a linear MDOF model for experimental modal analysis using a Timoshenko beam model and based on Anderson $\breve{s}$ criteria, (2) computation of the structure $\breve{s}$ response to a large set of accelerograms simulated by SIMQKE software, considering twelve ground motion parameters as intensity measurements (IM), and (3) construction of the fragility curves by comparing numerical interstorey drift with the threshold criteria provided by the Hazus methodology for the slight damage state. By introducing experimental data into the model, uncertainty is reduced to 0.02 considering $\mathrm{Sd}\left(\mathrm{f}_{1}\right)$ as seismic intensity IM and uncertainty related to the model is assessed at 0.03 . These values must be compared with the total uncertainty value of around 0.7 provided by the Hazus methodology.
\end{abstract}

KEY WORDS: vulnerability, fragility curves, uncertainty, slight damage, Timoshenko model, Bucharest 


\section{INTRODUCTION}

While the global rate of seismic activity remains constant, growing urbanisation increases the number of buildings and populations exposed to seismic hazards. Jackson (2006) considers that in view of the recurrence interval of mega-earthquakes with respect to the start of mega-city urbanisation, most huge urban centres around the world have not yet suffered a strong earthquake, which implies major urban catastrophes in the future. The assessment of seismic vulnerability in existing buildings is therefore a key issue for predicting and reducing seismic risk in modern industrialised societies. Empirical methods have been first developed for global scale assessment (e.g., FEMA, 2003a; GNDT, 1986; Risk-UE, 2003; Gueguen et al., 2007), based on expert opinions and post-earthquake observations. Damage matrices have been developed giving damage rates for a given seismic hazard, usually expressed in macroseismic intensity. These methods lead to high levels of uncertainty in predictions, due to poor knowledge of the design and behaviour of buildings, the complexity of structural damage mechanisms and the relationships between seismic ground motion and the damage state of the building (Michel et al., 2012).

Kappos et al. (2006) and Douglas (2007) suggest that the main problem in constructing empirical vulnerability functions or fragility curves (i.e., expressing the exceedance probability of a damage state for seismic ground motion parameters) is due to the lack of observational data for several ranges of ground motion or intensity measurements (IM). This problem becomes crucial in moderate seismic hazard prone regions, where the recurrence interval of significant earthquakes may be long. A direct consequence of the low number of observations is the higher level of uncertainty in the construction of fragility curves. One solution for significantly reducing uncertainty consists in improving our understanding of the building $\breve{s}$ response and its seismic behaviour in the event of an earthquake. Kappos et al. (2006) bypassed this difficulty by proposing a hybrid method, mixing empirical approaches and expert judgments for the moderate shaking, and nonlinear analysis for the highest intensities. Nevertheless, the second step requires a relevant definition of the building model, that remains difficult for a single existing building. Spence et al. (2003) claim that the main source of uncertainty is epistemic, due to the classification of buildings according to vulnerability and attributing generic behaviour to each construction class. Pinho et al. (2002) and Crowley and Pinho (2004) suggest using height-dependent relationships to estimate the vibration period of existing buildings, for integration into the performance-base methodology for vulnerability assessment. However, simplified relationships may introduce uncertainty in estimates of the fundamental period (Michel et al., 2010b; Gallipoli et al., 2010) which may ultimately increase fragility curve uncertainties.

One solution consists in using experiment data, such as the fitness of existing buildings model. Most of the scientific papers dealing with experimental testing under seismic loading focus on understanding their structural dynamics, seismic response or soil-structure interactions (e.g., Trifunac, 1972; Celebi et al., 1993; Bard, 1988; Meli et al., 1998; Ventura and Ding, 2000; Clinton et al., 2006; Todorovska and Trifunac, 2007) and rarely on how to integrate them into seismic vulnerability assessments. However, strategies that consist in improving model parameters using experimental results have been updated, mainly using ambient vibrations recordings (e.g., Volant et al., 2002; Michel et al., 2010a). For example, Michel et al. (2010b) provides height-period relationships for the design of French buildings based on the Operative Modal Analysis (OMA) method using ambient vibrations. This paper shows how the period can fix the first (elastic) part of capacity curves for existing buildings grouped in typologies and then reduce the epistemic uncertainties of the fragility curves. Boutin et al. (2005) proposes to integrate the experimental building analysis based on ambient vibrations for estimating the seismic integrity threshold, i.e. the boundary between the damaged and undamaged states, for a given seismic intensity. Michel et al. (2012) recently defined a methodology for defining experimental fragility curves for slight damage, proposing to reduce epistemic uncertainties by performing modal analysis of the buildings using 
ambient vibrations and considering slight damage as the end of the elastic domain of building behaviour.

Another solution is to introduce earthquake data recorded in the building to update its model and define its fragility curve. This solution improves understanding of the seismic response of a standalone structure to seismic loading and ultimately reduces the sigma value of its fragility curve, hereafter referred to as the single-building sigma. It also provides some analysis of the variability of the seismic response related to input seismic ground motion recorded at the bottom. This is the main objective of this paper, applied to a specific building in Romania, without considering the uncertainties from the material quality, the modelling or the boundary condition generally considered for numerical approach, but from the experimental data used to fix the building model. After describing the BRD Tower in Bucharest, a building with permanent instrumentation since 2003 (Aldea et al., 2004) and used as a case study in this paper, the Michel et al. (2012) method is briefly presented in the second part, with the adjustment for defining the modal model of the building using a Timoshenko beam model adjusted with experimental data explained in the third part. The originality of this paper is to provide new information on the uncertainties of building fragility curves, by testing the influence of two main sources of variability: the dynamic parameters of the building model and the input seismic ground motion IM also related to Earthquake Parameter Demand (EPD). This discussion is presented in the fourth part of this paper and finally the seismic vulnerability of the BRD tower is discussed and compared with an empirical assessment, based on the Hazus approach.

\section{THE BRD TOWER}

The BRD-Société Générale Bank high-rise building (Figure 1) was designed and built in 20012003 , in compliance with the provisions of the Romanian seismic design code P100-92. It is an office building with a dual reinforced concrete structure (inner shear-wall tube and perimeter frames), comprising 3 underground storeys, a ground floor and 18 storeys (Mironescu et al., 2003). The plane dimensions are about $26 \mathrm{~m}$ in the transversal (T) direction and $54 \mathrm{~m}$ in the longitudinal (L) direction. The tower is $74 \mathrm{~m}$ high. Based on PS logging measurements, average shear wave velocity over the upper $30 \mathrm{~m}$ at the BRD Tower site is $\mathrm{V}_{\mathrm{S}, 30 \mathrm{~m}}=284 \mathrm{~m} / \mathrm{s}$, (Aldea et al., 2006), which corresponds to Eurocode 8 ground type $\mathrm{C}$ (deep deposits of dense or medium dense sand, gravel or stiff clay with thickness from several tens to many hundreds of meters, $\mathrm{V}_{\mathrm{S}, 30 \mathrm{~m}}=180^{-} 360 \mathrm{~m} / \mathrm{s}$ ). Average shear wave velocity over a depth of $110 \mathrm{~m}$ is $354 \mathrm{~m} / \mathrm{s}$.

The building $\breve{s}$ seismic instruments were installed in 2003 as part of the Japan International Cooperation Agency (JICA) Technical Cooperation Project with Romania (JICA, 2002; Aldea et al., 2006). The instrumentation consists of one acquisition station (K2, Kinemetrics) with two tri-axial acceleration sensors (Episensor FBA ES-T, Kinemetrics), one sensor at the top of the building $(+69.6 \mathrm{~m})$ and the other one on the foundation slab, at the third underground level, $-9.3 \mathrm{~m})$. The sensors are located in an almost central position near the inner shear-wall tube, and the top and basement sensors are on the same vertical axis of the building (Aldea et al., 2007).

Since measurement started, several earthquakes have been recorded in the building. The list of recorded earthquakes used in this paper is given in Table 1. The largest is the 27/10/2004 $\left(\mathrm{M}_{\mathrm{W}}=6.0\right)$ earthquake, coming from the Vrancea subcrustal source region (focal depth between $60 \mathrm{~km}$ and $170 \mathrm{~km}$ ), located about $110-140 \mathrm{~km}$ north-east. Additional moderate to strong crustal events are also considered herein. 


\section{METHOD}

A fragility curve is generally given as the conditional probability $P[D=j \mid i]$ that a building exceeds a given damage state $\mathrm{j}$ for a given level of seismic input $\mathrm{i}$. The Hazus methodology (FEMA, 2003b) provides fragility curves for several classes of buildings and damage levels: slight, moderate, extensive and complete. In the literature, several functions exist for assessing seismic vulnerability using empirical (Spence et al., 1992; Orsini, 1999) or analytical (Onose, 1982; Singhal et al., 1997) approaches. A critical review of existing fragility curves can be found in Rossetto and Elnashai (2003). They are usually expressed by the cumulative distribution function of a normal (Spence et al., 1992) or most often lognormal (Milutinovic and Trendafiloski, 2003; FEMA, 2003a; McGuire, 2004) distribution. In this paper, a lognormal distribution is used, characterised by a median value $\approx$ and the corresponding lognormal standard deviation , such as:

$$
P(d>d s)[A]=\frac{1}{2}\left(1+e r f\left(\frac{\ln (A)-\ln (\mu)}{\sigma \cdot \sqrt{2}}\right)\right)
$$

where $d s$ is the damage level, $A$ the measurement of seismic intensity used as seismic demand, erf the error function, $\approx$ the median value and the standard deviation of the lognormal distribution.

In the Hazus (FEMA, 2003b) and Risk-UE (2003) philosophies, fragility curves are given for a class of structures rather than for a single building, and epistemic uncertainties are then included in the overall variability. Michel et al. (2012) divided the standard deviation of the fragility curve into three parts: mod corresponding to the lack of knowledge of the model or the behavioural differences within a single class, $I M$ related to seismic ground motion, i.e. due to selection of the seismic intensity parameter providing the least variability of building response, and finally dam related to the thresholds characterising the lower boundary of each damage state. Assuming their independence, total variance ${ }^{2}$ is given by:

$$
\sigma^{2}=\sigma_{\text {mod }}^{2}+\sigma_{I M}^{2}+\sigma_{d a m}^{2}
$$

A complete description of the method can be found in Michel et al. (2012), summarized here. This method implements a three-step procedure. The first step consists in adjusting the elastic multidegree-of-freedom (MDOF) model obtained by testing. The second step is the MDOF seismic

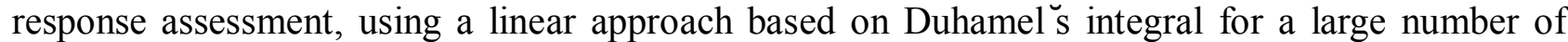
time history input motions, regularly distributed within a wide range of IM. Finally, the third step consists in computing for each range of IM the probability (number) of exceeding the damage threshold corresponding to slight damage. Only slight damage is considered here since the elasticlinear model is used, Michel et al. (2012) considering the elastic domain as being valid until the end of the undamaged state of the structure. The three steps are described hereafter in sections 3.1 to 3.3 and then applied to the BRD Tower.

\subsection{Step 1. The building model}

In this paper, the Frequency Domain Decomposition (FDD) technique (Brincker et al., 2001; Michel et al., 2008; Michel et al., 2010a) is applied to earthquake data in order to estimate the building frequencies. FDD is a non-parametric method, i.e. no a priori information of the building model is required. It consists in computing the Fourier spectra of the cross-correlation matrix of simultaneous recordings. Brincker et al. (2001) applied the Power Spectra Density to decompose the response into singular vectors (i.e. an estimate of the mode shapes $\mathbb{B}$ ) and scalar singular values (i.e. resonance frequencies). This method has been successfully applied to earthquake data (Ventura 
et al., 1995; Michel et al., 2008; Michel et al., 2010a) and comparison with numerical modelling (Turek et al., 2006; Michel et al., 2008, 2010a) shows the robustness of this method.

In order to confirm this robustness, twenty-five accelerograms recorded at the bottom and at the top of the building were processed using the FDD method. Three sets of accelerograms were considered (Table 2), depending on the magnitude of peak ground acceleration (PGA):

- Set 1: recordings with PGA $<3.5 \mathrm{~cm} / \mathrm{s}^{2}$, corresponding to 18 earthquakes;

- $\quad$ Set 2: recordings with PGA $>3.5 \mathrm{~cm} / \mathrm{s}^{2}$; corresponding to 7 earthquakes;

- Set 3: one single recording with PGA $=36.8 \mathrm{~cm} / \mathrm{s}^{2}$, corresponding to the strongest ground motion recorded since the building was instrumented (2004/10/27 earthquake, $\mathrm{M}=6.0$ ).

Table 2 provides the results of the modal analysis. The same values are obtained regardless of the level of shaking, so we can consider that the building $\breve{s}$ behaviour remains elastic. As the first set corresponds to the lowest intensities, the frequencies will be considered as characterising the elastic response of the BRD building hereafter. The frequencies of horizontal translations are $\mathrm{f}_{1 \mathrm{~T}}=1.11 \mathrm{~Hz}$ and $\mathrm{f}_{2 \mathrm{~T}}=4.56 \mathrm{~Hz}$ and $\mathrm{f}_{1 \mathrm{~L}}=1.47 \mathrm{~Hz}$ and $\mathrm{f}_{2 \mathrm{~L}}=5.82 \mathrm{~Hz}$, in the transverse (T) and longitudinal (L) directions, respectively, for the first (1) and second (2) modes, in agreement with previous results (Aldea et al., 2007).

Based on the $\mathrm{f}_{2} / \mathrm{f}_{1}$ ratio, a theoretical continuous beam model can be produced (Clough and Penzien, 1993): $f_{n}=(2 n-1) \cdot f_{1}$ and $f_{n}=((2 n-1) / 1.194)^{2} \cdot f_{1}$ for the shear and the bending beams, respectively. In practice, real buildings often have a frequency series in between these two models, resulting from the design of the structure associating shear and bending behaviour. In this paper, the Timoshenko beam model is used (Boutin et al., 2005). The equation of the behaviour becomes (Hans, 2002):

$E l \frac{\partial^{4} \Phi(x)}{\partial x}+\frac{E l}{K} m \omega^{2} \frac{\partial^{2} \Phi(x)}{\partial x}-m \omega^{2} \Phi(x)=0$

where $E I$ and $K$ corresponds to the bending and shear stiffness, respectively. A dimensionless parameter $\mathrm{C}$ is introduced as the ratio between the bending and the shear behaviour (Hans et al., 2005; Michel et al., 2006):

$C=\frac{E l}{K L^{2}}$

where $\mathrm{L}$ is the pseudo-length of the beam $(\mathrm{L}=\mathrm{H} / 2(\mathrm{u})$ with $\mathrm{H}$ the length of the beam). Having obtained the frequency ratio $\mathrm{f}_{\mathrm{k}} / \mathrm{f}_{1}$, the Timoshenko parameter $\mathrm{C}$ can be calculated using the following formula:

$$
\frac{f_{k}}{f_{1}}=\frac{\delta_{k}^{2}}{\delta_{1}^{2}} \frac{\sqrt{1+\delta_{1}^{2} C}}{\sqrt{1+\delta_{k}^{2} C}}
$$

where $k$ is a series of dimensionless wave numbers $(k \bar{u} 2 k+1$ for $k \hbar 2)$.

Finally, knowing the $\mathrm{k}$ series and parameter $\mathrm{C}$, the theoretical mode shapes are expressed as 
follows (Hans, 2002):

$$
\begin{gathered}
\Phi_{k}(x)=\frac{\delta_{k}^{4}}{1+C \delta_{k}^{2}}\left[\frac{\delta_{k}}{\sqrt{1+C \delta_{k}^{2}}} \sinh \left(\frac{\delta_{k}}{\sqrt{1+C \delta_{k}^{2}}} \frac{\pi}{2}\right)+\delta_{k} \sin \left(\delta_{k} \frac{\pi}{2}\right)\right]\left[\cosh \left(\frac{\delta_{k}}{\sqrt{1+C \delta_{k}^{2}}} \frac{\pi x}{2 H}\right)-\sin \left(\delta_{k} \frac{\pi x}{2 H}\right)\right] \\
-\left[\delta_{k}^{2} \cosh \left(\frac{\delta_{k}}{\sqrt{1+C \delta_{k}^{2}}} \frac{\pi}{2}\right)+\frac{\delta_{k}}{1+C \delta_{k}^{2}} \cos \left(\delta_{k} \frac{\pi}{2}\right)\right]\left[\frac{\delta_{k}^{3}}{\left(1+C \delta_{k}^{2}\right)^{3 / 2}} \sinh \left(\frac{\delta_{k}}{\sqrt{1+C \delta_{k}^{2}}} \frac{\pi x}{2 H}\right)-\delta_{k}^{3} \sin \left(\delta_{k} \frac{\pi x}{2 H}\right)\right]
\end{gathered}
$$

For $\mathrm{C}=0$, the Timoshenko beam corresponds to a pure bending beam, whereas for $\mathrm{C}=+\overline{\mathrm{e}}$, it corresponds to a pure shear beam (Figure 2). According to Boutin et al. (2005), a structure can be considered as having the same behaviour as a pure bending beam if $\mathrm{C}<0.05$ and the same behaviour as a pure shear beam if $\mathrm{C}>5$. The comparisons made by Boutin et al. (2005) and Michel et al. (2006) confirm the reliability of the Timoshenko model compared to that obtained by ambient vibrations on existing buildings using OMA techniques. Perrault and Gueguen (2010) also examine the efficiency of this model for computing experimental fragility curves.

The major advantage of this approach that must be underlined is the frequency ratio that can be easily obtained by frequency analysis of short-time recordings of ambient vibrations done only at the top of the structure giving the modal model of the existing structure, without any design or material assumptions. In our case, the BRD-Tower corresponds to Timoshenko models $\mathrm{C}_{\mathrm{T}}=0.159$ and $C_{L}=0.195$, in the transverse and longitudinal directions, respectively. The value of the $C$ coefficient is similar to those given by Michel et al. (2006) and corresponds to this category of buildings. The shear effect is more important than the bending effect, also confirmed by the mode shapes (Figure 3). In this paper, two MDOF models are defined, taking into account the frequency ratios in both horizontal directions and using Eq. 6 .

\subsection{Step 2. The MDOF building response}

Assuming a building of regular mass and stiffness distribution, the BRD-Tower is modelled using one MDOF-1D linear lumped mass model for both the transverse and longitudinal directions. Knowing the modal parameters, i.e. frequencies, damping and mode shapes, the displacement vector $\{U(t)\}$ at each floor of the structure is computed for any ground motion displacement vector $\left\{U_{s}(t)\right\}$ using the equation (Clough and Penzien, 1993):

$$
\{U(t)\}=[\Phi]\{y(t)\}+U_{s}(t)
$$

where $y(t)$ is determined using the Duhamel $\breve{s}$ integral :

$$
y(t)=\sum_{j=1}^{N} \frac{-p_{j}}{\omega_{D j}} \int_{0}^{t} \ddot{U}_{s}(t) e^{-\zeta \omega_{j}(t-\tau)} \sin \left(\omega_{D j}(t-\tau)\right) d \tau
$$

with $\omega_{D j}^{2}=\omega_{j}^{2}\left(1-\zeta_{j}^{2}\right)$ the damped angular frequency,

$$
p_{j}=\frac{\left\{\Phi_{j}\right\}^{T}[M]\{1\}}{\left\{\Phi_{j}\right\}^{T}[M]\left\{\Phi_{j}\right\}}=\frac{\sum_{i=1}^{N} \Phi_{i j}}{\sum_{j=1}^{N} \Phi_{i j}^{2}}
$$

the number of storeys and $B, \cdot \because$ and $\ll$ the mode shapes, damping ratios and frequencies of the building, respectively. 
The higher modes are then accounted for the building $\breve{s}$ response and no additional information on mass and rigidity distributions is required. Michel et al. $(2008,2010 \mathrm{a}, 2012)$ tested the efficiency of this approach compared with real data and numerical modelling to reproduce the elastic building motion under moderate shaking, although 3D behaviour including torsion mode and soil-structure interaction effects are not included in the model. In this paper, the damping ratio was obtained by adjusting synthetic to real data according to Anderson $\breve{s}$ criteria (Anderson, 2004), discussed in the following section.

\subsection{Step 3. The fragility curves}

In the literature, several different measurements of seismic intensity for input motion are considered as being well correlated with damage (e.g. Cabanas et al., 1997; Wald et al., 1999). These parameters correspond to the intensity measurement (IM) of ground motion in engineering seismology and called sometimes Engineering Demand Parameters (EDP) in earthquake engineering. In this paper, thirteen different ground motion parameters named $\mathrm{P}_{\mathrm{IM}}$ (i.e. parameter of ground motion intensity measurement) are considered for the fragility curves: peak ground acceleration (PGA), velocity (PGV) and displacement (PGD), spectral displacement $\left[\operatorname{Sd}\left(\mathrm{f}_{1}, \bullet^{i}\right)\right.$,

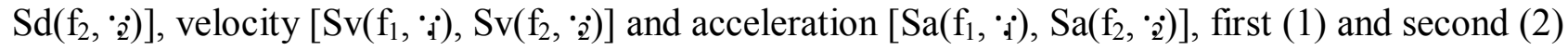
modal frequencies, Arias Intensity (Ia; Arias, 1970), Housner Intensity (Ih; Housner, 1952) and Cumulative Absolute Velocity (CAV; EPRI, 1991).

Seismic input motions were generated using the SIMQKE procedure (Gasparini and Vanmarcke, 1976), taking several classes of EC8 response spectra (CEN, 2003) as targets. Using this procedure, a wide range of seismic demand values (from weak to strong) was obtained, a key condition for constructing a continuous fragility curve. In the original code, a white-noise time series was filtered with a trapezoidal envelope in time. The phase of the output time histories was chosen randomly. In a previous study (Perrault and Gueguen, 2010; Causse et al., 2013), we modified the original version by using natural phase accelerograms to obtain more realistic output time histories. Natural accelerograms were selected from the French Accelerometric Network database (RAP, Péquegnat $e t$ al., 2008), corresponding to moderate seismic hazard prone regions, with the same range of magnitude and distance as Romania. Only data corresponding to earthquakes with magnitude $\mathrm{M}>4$, focal depth less than $10 \mathrm{~km}$, and recorded at epicentral distances of less than $40 \mathrm{~km}$ were selected, corresponding to 18 events and 36 records. For each component, 32 synthetic accelerograms were generated, with target spectra defined in Eurocode 8 and corresponding to:

The four main classes of buildings (i.e. class I: buildings of minor importance for public safety; class II: ordinary buildings, not belonging in the other categories; class III: buildings whose seismic resistance is important in view of the consequences associated with collapse; class IV: buildings whose integrity during earthquakes is of vital importance.

Four intervals of accelerations were considered, equivalent to moderate seismic hazard prone regions: low seismicity, with a peak ground acceleration $\mathrm{a}_{\mathrm{g}}$ of $0.7 \mathrm{~m} / \mathrm{s}^{2} \mathrm{Ha} \mathrm{a}_{\mathrm{g}}<1.1 \mathrm{~m} / \mathrm{s}^{2} ;$ moderate seismicity, with $1.1 \mathrm{~m} / \mathrm{s}^{2} \mathrm{Ha}_{\mathrm{g}}<1.6 \mathrm{~m} / \mathrm{s}^{2} ;$ medium seismicity, with $1.6 \mathrm{~m} / \mathrm{s}^{2} \mathrm{Ha} \mathrm{a}_{\mathrm{g}}<3.0 \mathrm{~m} / \mathrm{s}^{2} ;$ high seismicity, with $3.0 \mathrm{~m} / \mathrm{s}^{2} \mathrm{Ha}$.

The two types of earthquakes (i.e. type 1 earthquakes corresponding to moderate to high seismic regions (with a surface magnitude $\mathrm{Ms}>5.5$ ) and type 2 earthquakes corresponding to low seismic regions ( $\mathrm{Ms}<5.5)$ and near field earthquakes).

Site conditions of the RAP stations were kept for the soil class of the target response spectra. A total of 2304 synthetics are finally considered in this paper.

Finally, the damage is computed based on the FEMA (2003a) document which provides, for each 
building class, thresholds for each damage state based on the inter-storey drift (ISD) limit. ISD is computed as the relative displacement of one storey divided by storey height. For each range i of

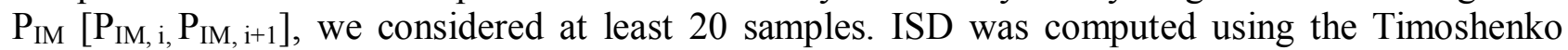
model (Eq. 9) and the Duhamel integral (Eq. 11). The number of runs exceeding the drift limit corresponding to FEMA $\breve{s}$ slight damage state leads to the probability $\mathrm{P}[\mathrm{d} \hbar$ `slight_]. This limit is chosen to be in conformity with the elastic and linear validity of the model based on moderate to small shaking, as proposed by Michel et al. (2012). Finally, the process was repeated for all

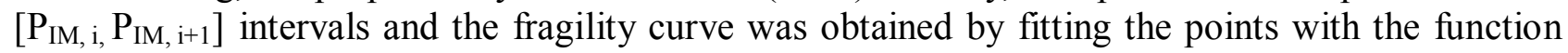
described in Eq. 1. The lognormal standard deviation obtained at this step corresponds to the uncertainty $I M$ relative to the seismic hazard (Eq. 2).

\section{ADJUSTING THE BRD MODEL USING THE ANDERSON`S CRITERIA}

In this paper, and using the Timoshenko $\breve{s}$ beam modelling strategy for the building, damping is not directly extracted from the data. In order to avoid discussions on the damping value assessment using existing methods and its variation with building deformation, we tested several damping values to adjust the BRD model. Time histories of building motion at the top were computed using equations 6 to 8 considering ten values of damping $(0.1,0.5,1,2,3,4,5,6,7$ and $10 \%)$ and compared with observations. Fives modes were considered for the model in both horizontal directions and for the twenty-five available earthquakes (Table 1). The synthetics and observations were compared using the Anderson criteria (Anderson, 2004). As suggested by Anderson, six frequency ranges were considered for computing goodness-of-fit: [0.5-1.0], [1.0-2.0], [2.0-5.0], [5.0-10.0], [10.0-20.0] and [0.5-20.0] Hz. After filtering the accelerograms on each frequency band, ten parameters were compared: peak acceleration (pga), peak velocity (pgv), peak displacement (pgd), Arias intensity (Ia), integral of velocity squared (Iv), Fourier spectrum (fs), acceleration response on a frequency-by-frequency basis $(\mathrm{Sa})$, shape of the normalised integrals of acceleration (Da), velocity squared (De) and cross correlation $\left(C^{*}\right)$. Anderson applied these criteria to seismic ground motion recordings and some parameters may not be adapted to the building $\breve{s}$ response (e.g., response spectra in the building). Nevertheless, all the parameters proposed by Anderson were considered in this study and we used the same names for the criteria. For each parameter para, a score $S_{\text {para }}$ was computed giving values between 0 and 10: according to Anderson (2004), a score below 4 indicates poor fit, a score between 4 and 6 a fair fit, a score between 6 and 8 a good fit and a score over 8 an excellent fit.

Figure 4 shows an example of the 2D radar chart representation of Anderson $\breve{s}$ criteria corresponding to the strongest seismic intensity (Table 1, 27/10/2004 earthquake, $\mathrm{M}_{\mathrm{W}}=6.0$ ) recorded in the $\mathrm{T}$ direction and considering the Timoshenko model with $1 \%$ damping. This figure displays a summary of goodness-of-fit for the six frequency ranges, criterion by criterion. In this example, all the criteria are over 6 (good fit), except for the $\mathrm{S}_{\mathrm{fs}}$ criterion (poor fit). Anderson (2004) assumes this criterion usually provides the most restrictive score because it requires that the Fourier amplitude fits at each frequency.

Figure 5A shows the best goodness-of-fit of Anderson $\breve{s}$ criteria results for several damping values and considering the twenty-five earthquakes (Table 1). Both $\mathrm{T}$ and $\mathrm{L}$ directions were considered, and the scores were computed by averaging the scores corresponding to the six frequency ranges. The higher scores were obtained for damping equal to $1 \%\left(S_{\text {average }}=6.61\right)$ and $4 \%\left(S_{\text {average }}=5.97\right)$, in the $\mathrm{T}$ and $\mathrm{L}$ directions, respectively. For this value of damping in the $\mathrm{T}$ direction, all scores were over 6 (good fit) with $\mathrm{S}_{\mathrm{Da}}$ and $\mathrm{S}_{\mathrm{De}}$ scores over 8 (excellent fit), except for $\mathrm{S}_{\mathrm{fs}}$, whose values were between 2 and 4 (poor fit). In the L direction, six criteria presented a score over 6 (good fit), three had a score between 4 and 6 (fair fit) and the $S_{\text {fs }}$ score remained below 4 (poor fit). 
The effect of the frequency band is shown in Figure 5B considering the same values of damping and the twenty-five earthquakes. The lowest goodness-of-fit was obtained in the range [5.0$10.0] \mathrm{Hz}$, and [5.0-10.0] and [0.5-1.0] Hz, in the $\mathrm{T}$ and $\mathrm{L}$ directions, respectively. For the ranges corresponding to the first two frequencies of the building, i.e. [1.0-2.0] Hz and [2.0-5.0] Hz, the average score of the Anderson $\breve{s}$ criteria is over 8 , i.e. the fit between synthetics and observations is excellent.

To conclude, the Anderson criteria analysis gives experimental validation of the simplified models of the BRD building in the range of shaking level produced by the earthquakes. Two different Timoshenko models were defined in order to represent the building $\breve{s}$ behaviour in the two horizontal directions. The models are different because they were defined on the basis of different values of frequency ratios and different values of damping: $\mathrm{C}_{\mathrm{T}}=0.159, \mathrm{f}_{1 \mathrm{~T}}=1.11 \mathrm{~Hz}$ and $\cdot \dot{\mathrm{T}}=1 \%$ in the $\mathrm{T}$ direction and $\mathrm{C}_{\mathrm{L}}=0.195, \mathrm{f}_{1 \mathrm{~L}}=1.48 \mathrm{~Hz}$ and $\ddot{\mathrm{i}}=4 \%$ in the $\mathrm{L}$ direction.

\section{UNCERTAINTIES OF THE FRAGILITY CURVES}

As assumed by Spence et al. (2003), the lack of knowledge regarding existing building models contributes to the uncertainties of fragility curves, called mod in Eq. 2. Other uncertainties come from the relationships between the seismic intensity parameters and the damage state, called $I M$. In this paper, we tested the effects of the variability of the modal parameters, i.e. frequency and damping, and of the ground motion parameters on the fragility curve, computed according to the aforementioned methodology. This uncertainty is directly related to the standard deviation of the lognormal distribution given Eq. 1. Uncertainty resulting from the damage threshold dam was not studied. Nevertheless, since the BRD Tower was initially classified as belonging to the $\mathrm{C} 1 \mathrm{H}$ class of the Hazus typology, i.e. a RC moment resisting frame building with at least 8 storeys, with an earthquake provision corresponding to the Moderate Code design level, the ISD threshold corresponding to slight damage is $0.0025 \mathrm{~m} / \mathrm{m}$ and dam is proposed to be 0.4 (FEMA, 2003a). This uncertainty (and those found in this manuscript) corresponds to the sigma of the log-normal distribution (Eq. 1) with the origin given Eq. 2. Even if the threshold value is provided by Hazus as the half of the regular value to account for higher modes, we kept this threshold as reference in our methodology in case of only the fundamental mode can be detected by experimental data (as for small buildings).

\subsection{Uncertainty due to the seismic demand IM}

In this section, we only consider the model of the BRD Tower in the transverse direction $\left(\mathrm{C}_{\mathrm{T}}=0.159\right)$ with $1 \%$ damping. To test the effects of seismic intensity, we considered a given model $(\bmod =0)$ and a given ISD threshold $\left(\mathrm{dam}_{\mathrm{d}}=0\right)$. In Figure 6 , fragility curves are shown for the twelve ground motion parameters $\mathrm{P}_{\mathrm{IM}}$ representing noxiousness of seismic ground motion computed using the 2304 synthetic ground motions described in section 3.3. $\operatorname{Sd}\left(f_{1}\right), \operatorname{Sv}\left(f_{1}\right)$ and $\operatorname{Sa}\left(f_{1}\right)$ provide very slight uncertainties ( $I M=0.02,0.05$ and 0.02 , respectively). This result shows that the median value of the fragility curve gives almost the exact value of the seismic intensity parameter between the damaged and undamaged states. As expected, others parameters, such as PGA or Arias intensity, provide higher values of variability ( 0.62 and 0.83 respectively), indicating that they are not well correlated with damage. PGV gives a rather limited value of sigma (0.286), confirming that velocity is fairly representative of the noxiousness of seismic ground motion, as already mentioned in empirical observations (e.g. Wald et al., 1999). 
Sigma values corresponding to $\operatorname{Sd}\left(\mathrm{f}_{2}\right), \operatorname{Sv}\left(\mathrm{f}_{2}\right)$ or $\operatorname{Sa}\left(\mathrm{f}_{2}\right)$ at the second frequency are higher than at the first frequency. In this case, the fundamental mode seems to control the building $\breve{s}$ response. However, as mentioned by Seyedi et al. (2010), the second mode may also contribute significantly to the building $\breve{s}$ response and to the seismic damage observed in buildings, depending on the resonance phenomena observed at this frequency with the seismic input motion.

\subsection{Uncertainty due to the model mod}

In this part, we analyse the variability mod due to the model, i.e. frequency and damping values, considering a single building and several input ground motions. Nayeri et al. (2008) studied the variations of the modal frequencies and damping in the Factor Building, a 17-story steel frame structure located on the UCLA campus, in California. The authors monitored the dynamic characteristics of this structure using ambient vibration recordings over 50 days. The results showed a variation of about $1-2 \%$ for the first modal frequencies $\left(\left(f_{1}\right)=0.01\right.$ and $\left.\left(f_{2}\right)=0.02\right)$, and between 30 and $60 \%$ for damping $(\quad(\cdot)=2.015)$. Mikael et al. (2013) carried out similar studies on two French 31-storey and 15-storey RC buildings, based on ambient vibrations recorded over one year. They found similar frequency variations, namely about $1 \%\left(\left(f_{1}\right)=0.01\right.$ and $\left.\left(f_{2}\right)=0.02\right)$, although the damping variations were less than those reported by Nayeri et al., i.e. between 10 and $30 \%((;)=0.2)$. Although the origin of the natural wandering of modal parameters is still under discussion (e.g., type of construction, soil-structure interaction, weather conditions, uncertainties in measurements and processing), we tested the effects of these slight variations on fragility curves. In the section below, a constant elastic frequency is assumed, even if slight frequency variations can be observed before the yield point in experimental data.

First, with constant damping ( $\because=1 \%$ for $i \square[1 ; 5])$ and according to the sigma values provided by Nayeri et al. (2007) and Mikael et al. (2013), a distribution of 100 frequencies $\mathrm{f}_{1}$ and $\mathrm{f}_{2}$ was used, with median values given by the results of transversal direction processing $\left(\mathrm{f}_{1}=1.11 \mathrm{~Hz}\right.$; $\mathrm{f}_{2}=4.57 \mathrm{~Hz}$, Table 3) considering $1 \%$ damping. We assumed a lognormal distribution of frequencies, as observed by Mikael et al. (2013). Timoshenko models with $\mathrm{C}$ values corresponding to the $100 \mathrm{f}_{2} / \mathrm{f}_{1}$ ratios were computed, giving 100 fragility curves (Figure 7). Since $\operatorname{Sd}\left(\mathrm{f}_{1}, \because i\right)$ provides the smallest $I M$ value, this ground motion parameter was conserved for seismic demand. The same lognormal distribution was considered in order to test the effect of damping variations (Table 3) with constant modal frequencies and the results are shown in Figure 8.

For each fragility curve, the standard deviation corresponds to the variabilities $I M$ and $m o d$. Since uncertainties $I M$ and ${ }_{\bmod }$ are considered to be independent, we can write the different uncertainties according to two formulae:

$$
\sigma_{\text {dist }, f}^{2}=\sigma_{\text {mod, } f}^{2}+\sigma_{I M}^{2}
$$

and

$$
\sigma_{\text {dist }, \zeta}^{2}=\sigma_{\bmod , \zeta}^{2}+\sigma_{I M}^{2}
$$

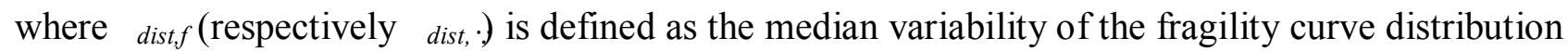
corresponding to the frequency distribution (respectively damping distribution) and mod, $f$ (respectively mod, ) is defined as the uncertainty due to frequency variations (respectively damping variations) in the model. Uncertainty ${ }_{\text {mod }}$ is then deduced from the median standard deviation of the fragility curve distribution and the previously defined estimated term $I M$. Considering the effects of frequency and damping as being independent, mod can be defined as: 
The frequency distributions reported by Nayeri et al. (2008) or Mikael et al. (2013) provide similar dist,, , with low variation coefficients $/ \approx$, i.e. $24.7 \%$ and $27.0 \%$, respectively: the values of and $\approx$ are given in Figure 7 . The mean values of variability dist, $f$ are similar, i.e. $\approx=0.02$ and $\approx=0.02$,

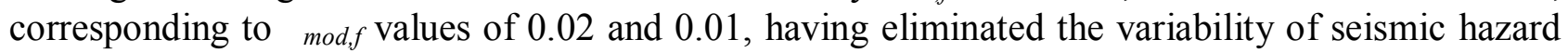
according to Eq. 9.

For damping, the coefficients of variations $\quad / \approx$ of the distributions are higher, because of the larger variability considered in the two distributions: $\quad / \approx=43.4 \%$ for the Nayeri et al. distribution and $/ \approx=20.1 \%$ for the Mikael et al. distribution: the values of and $\approx$ are given in Figure 8 . However, the median values $\approx$ remain close to one another, corresponding to $\bmod , \because$ values equal to 0.02 and 0.01 having removed haz according to Eq. 10 .

Finally, an estimate of the variability due to the model can be computed using Eq. 14. Considering lognormal distributions for frequency and damping variations, mod values are 0.028 and 0.020 for the Nayeri et al. (2008) and Mikael et al. (2013) distributions, respectively, i.e. the same order of magnitude as the uncertainties $I M$ given by the seismic intensity parameters (e.g. 0.02 and 0.05 for $\operatorname{Sd}\left(\mathrm{f}_{1}\right)$ and $\left.\operatorname{Sv}\left(\mathrm{f}_{1}\right)\right)$. Keeping ${ }_{d a m}=0.40$ as given by FEMA (2003a), mod $=0.03$ and $I M=0.02$, this results in a total uncertainty $=0.40$, according to Eq. 2 . The use of experimental data to adjust the elastic model of existing buildings (i.e., frequency, damping and mode shape, not discussed here) can be helpful for reducing the epistemic uncertainty of the fragility curve. Compared to the Hazus guidelines, which recommend a lognormal standard deviation of the fragility curves equal to 0.7 , the gain of the experimental approach to reducing the uncertainties of fragility curves is significant. Furthermore, and also as mentioned by Michel et al. (2010a, 2012), in situ testing, using earthquake or ambient vibration recordings, may help to fix the theoretical building model that is often difficult to apply to existing buildings.

\section{SEISMIC VULNERABILITY OF THE BRD TOWER}

In this section, the previously defined uncertainties are taken into account to define the fragility curve of the BRD Tower, i.e. $I M=0.02$ and ${ }_{\text {mod }}=0.03$. Uncertainties dam due to the ISD threshold value corresponding to slight damage were assumed to equal 0.4 . The frequency ratios $\mathrm{f}_{2} / \mathrm{f}_{1}$ for the $\mathrm{T}$ and $\mathrm{L}$ directions observed using earthquake data lead to a Timoshenko model which does not correspond to pure bending or shear models (Figures 2 and 3). In addition to the $\mathrm{C} 1 \mathrm{H}$ structural type initially considered, we also considered the $\mathrm{C} 2 \mathrm{H}$ type, i.e. a $\mathrm{RC}$ shear wall building, also with a moderate design level. Consequently, two ISD thresholds corresponding to slight damage were considered in order to define fragility curves: $0.0025 \mathrm{~m} / \mathrm{m}$ for the $\mathrm{C} 1 \mathrm{H}$ type and $0.0020 \mathrm{~m} / \mathrm{m}$ for the C2H type (FEMA, 2003a).

The experimental fragility curves displayed in Figure 9 are very similar in both horizontal directions, the effects of the differences of the modal parameter (frequency and damping) on the fragility curves being reduced by considering the same mod. The largest difference comes from the choice of building type. For types $\mathrm{C} 1 \mathrm{H}$ and $\mathrm{C} 2 \mathrm{H}$, fragility curve differences are significant due to the differences in ISD threshold values. This observation confirms the importance of building model knowledge as well as the importance of reducing dam in future analyses. Moreover, compared to Hazus fragility curves, smaller variabilities were observed, leading us to conclude that experimental data makes an efficient contribution to seismic vulnerability assessment. The main gain is the reduction of epistemic uncertainties due to the model, and this approach can contribute 
significantly to improving the vulnerability assessment of single existing buildings, for the slight damage state only. This solution improves the single-building vulnerability assessment since it does not require the selection of one generic fragility curve providing for example by Hazus methodology and corresponding to one class of typology and with a large epistemic uncertainty.

Since only ISD thresholds and dam provided by Hazus are available, the $\mathrm{C} 2 \mathrm{H}$ and $\mathrm{C} 1 \mathrm{H}$ fragility curves are considered here as being the upper and lower boundaries of the BRD slight damage probabilistic curve, which defines a fragility area represented in grey in Figure 9. The source of Hazus uncertainties can be considered as different of those defined in our methodology. The comparison displayed in Figure 9 is done for showing the gain provided by introducing experimental data in the definition of the building model. For example, for an $\operatorname{Sd}\left(\mathrm{f}_{1}\right)$ value equal to $0.1 \mathrm{~m}$, the probability of at least slight damage is $57 \% \pm 13 \%$. According to the $\mathrm{P} 100-1 / 2006$ Romanian seismic design code (Figure 10), the values of spectral displacement at the first frequencies of the BRD Tower are $\mathrm{S}_{\mathrm{De}}\left(\mathrm{f}_{1 \mathrm{~T}}\right)=0.13 \mathrm{~m}$ and $\mathrm{S}_{\mathrm{De}}\left(\mathrm{f}_{1 \mathrm{~L}}\right)=0.09 \mathrm{~m}$. These values provide slight damage probabilities between 25 and 49\% (respectively between 74 and 89\%) in the L direction (respectively in the $\mathrm{T}$ direction) for the design demand, corresponding to 475 -year return period. In comparison, the strongest earthquake recorded in the structure is the 27/10/2004 earthquake (Table 1) that caused no damage to the BRD Tower. For this earthquake, $\operatorname{Sd}\left(\mathrm{f}_{1}\right)$ were $0.24 \mathrm{~cm}(\mathrm{~T})$ and $0.32 \mathrm{~cm}(\mathrm{~L})$, corresponding to a $\mathrm{P}[\mathrm{d} \hbar$ `slight_] of $0 \%$. The comparison with the Vrancea earthquake and the Romania regulation should be confirmed but as this step, the relevancy of the fragility curve provided for this building is roughly confirmed.

\section{CONCLUSION AND PERSPECTIVES}

Seismic vulnerability analysis can be improved by reducing the uncertainties of fragility curves. One major source of such uncertainties is the lack of knowledge of building characteristics, causing a large range of epistemic uncertainties in fragility curves. Application to a large number of buildings becomes difficult and Calvi et al. (2006) concluded that most of the available methods fail to meet requirements.

This study shows how experimental testing may help to solve this challenge at least in part. Experimental data can be helpful for defining the elastic model of existing buildings, reducing epistemic uncertainties and then improving the empirical assessment of seismic vulnerability. In this paper, earthquake data were used to define the building model using a Timoshenko beam. The Anderson criteria (Anderson, 2004) allowed selection of the best model, based on goodness-of-fit between synthetics and recorded data, and enabled distinction between two different behaviours in both horizontal directions. We were then able to imagine a simple procedure using only the two first modal frequencies defined from ambient vibrations and allowing construction of a theoretical MDOF model. The ambient vibrations approach requires only 15 -minute recordings at the top of a building, which implies a large number of potential applications for assessing the seismic vulnerability of large cities. Since the model is relevant only for slight damage, this method becomes helpful in moderate seismic hazard prone countries where such earthquakes may cause slight to moderate damage and considerable economic losses, such as during the Ossau-Arudy $\left(1980, M_{L}=5.2\right)$ and Annecy $\left(1996, M_{L}=4.8\right)$ earthquakes, which caused approximately B3 million and B45 million of damage, respectively, or during the moderate Canadian earthquake (Forks Sand, New York, April 20, 2002, Mw = 5.0) which caused \$15 million in repairs (Pierre and Montagne 2004).

In this paper, the study of uncertainties due to the choice of seismic intensity parameters and the variations of experimental models makes a significant contribution to reducing the total uncertainty found in the literature. As expected, we showed that for this damage state, the spectral values are the 
IM that are most representative to the noxiousness of the ground motion, considering inter-storey drift as a damage criterion. Uncertainties are equal to 0.02 for $\mathrm{Sd}\left(\mathrm{f}_{1}\right)$. Experimental model variations led to uncertainties less than 0.03 , which confirms the efficiency of this approach. These values must be compared with the total uncertainties of 0.7 provided by Hazus. Nevertheless the ideal method should also provide an assessment of uncertainty due to the damage criterion, which remains the main component of fragility curve uncertainty. Little information is available and most results are given based on numerical approaches or laboratory experiments. The need for experimental data, such as that provided by buildings under permanent monitoring, could help reduce this uncertainty. This study could benefit future developments, such as proposing a hybrid method based on experimental testing for slight and moderate damage levels and modelling for the highest damage states.

In the case of a single building, such as the BRD Tower analysed here, this approach provides information on the model that can be relevant to fixing the elastic conditions of a 3D numerical model used to study the inelastic response in the event of stronger shakings. Also, it gives a level 0 (fast and cheap) estimate of the vulnerability of a single existing building in order to predict whether the building will suffer at least slight damage in a ground motion scenario.

For buildings designed without seismic provisions, slight damage may be of significant interest since the low ductility of existing buildings designed without seismic provision and building collapse occurs rapidly once the yield point is passed.

\section{ACKNOWLEDMENTS}

This work has been supported by the ANR national research agency as part of its RiskNat program (URBASIS project, no. ANR-09-RISK-009).

\section{REFERENCES}

Aldea A, Kashima T, Lungu D, Vacareanu R, Koyama S and Arion C (2004), 'Modern Urban Seismic Network in Bucharest, Romania,_ Proceedings of the First International Conference on Urban Earthquake Engineering, Tokyo Institute of Technology, Japan.

Aldea A, Kashima T, Poiata N, and Kajiwara T (2006), `A New Digital Seismic Network in Romania with Dense Instrumentation in Bucharest _, Proceedings of First European Conference on Earthquake Engineering and Seismology, Geneva, Switzerland.

Aldea A, Iiba M, Demetriu S and Kashima T (2007), 'Evidence of Soil-Structure Interaction from Earthquake Records at a High-Rise Building Site in Bucharest,_. Proceedings of the $4^{\text {th }}$ International Conference on Earthquake Geotechnical Engineering, Thessaloniki, Greece, paper 1523 .

Anderson JG (2004), 'Quantitative measure of the goodness-of-fit of synthetic seismograms, Proceedings of the $13^{\text {th }}$ World Conference on Earthquake Engineering, Vancouver, Canada, paper 243.

Arias A (1970), 'A measure of earthquake intensity _, in Seismic design for nuclear power plants, R.J. Hansen, ed., MIT Press, Cambridge, MA438-483.

Bard PY (1988), 'The importance of rocking in building motion: an experimental evidence, Proceedings of the Ninth World Conference on Earthquake Engineering, Tokyo ${ }^{-}$Kyoto, 8:333 ${ }^{-}$ 338.

Brincker R, Zhang L and Andersen P (2001) 'Modal identification of output only systems using Frequency Domain Decomposition, _ Smart Materials and Structures, 10, 441-445.

Boutin C, Hans S, Ibraim E and Roussillon P (2005), 'In situ experiments and seismic analysis of existing buildings. Part II: Seismic integrity threshold,_Earthquake Engineering and Structural 
Dynamics, 34 (12): 1531-1546.

Cabañas L, Benito B and Herraiz M (1997), `An Approach to the measurement of the potential structural damage of earthquake ground motions,_. Earthquake Engineering and Structural Dynamics, 26(1): 79-92.

Calvi G, Pinho R, Magenes G, Bommer J, Restrepo-Velez L and Crowley H (2006), `Development of seismic vulnerability assessment methodologies over the past 30 years, _ Indian Society Journal of Earthquake Technology, 43(3): 75-104.

Causse M, Laurendeau A, Perrault M, Douglas J, Bonnilla LF and Gueguen P (2013) `A set of Eurocode 8-compatible synthetic time-series as input to dynamic analysis, _ submitted to Bulletin of Earthquake Engineering.

Celebi M, Phan LT and Marshall RD (1993), 'Dynamic characteristics of five tall buildings during strong and low-amplitude motions, _. The Structural Design of Tall Buildings, 2(1): 1-15.

CEN. Eurocode 8: Design of structures for earthquake resistance. Part 1: general rules, seismic actions and rules for buildings. European Standard EN 1998-1:2004, Comité Européen de Normalisation, Brussels, Belgium, 2004.

Clinton J, Bradford SC, Heaton TH and Favela J (2006), 'The observed wander of the natural frequencies in a structure, _Bulletin of the Seismological Society of America, 96(1): 237-257.

Clough RW and Penzien J (1993), Dynamics of Structures. Mc Graw-Hill: New-York.

Coburn A and Spence R (2002), Earthquake Protection, John Wiley and Sons, Ltd.

Crowley H and Pinho R (2004), 'Period-height relationship for existing European reinforced concrete buildings, _ Journal of Earthquake Engineering, 8(1): 93-119.

Demetriu S and Aldea A (2006), 'Recorded Seismic Response of an Instrumented High-Rise Reinforced-Concrete Building in Bucharest,_. First European Conference on Earthquake Engineering and Seismology, Geneva, Switzerland, 3-8 September, Paper 777.

Douglas J (2007) 'Physical vulnerability modelling in natural hazard risk assessment, _ Natural Hazards and Earth System Sciences, 7(2): 283־288.

EPRI (1991), Standardization of the cumulative absolute velocity, EPRI 1R-100082 report, Electric Power Research Institute, Palo Alto, CA.

Federal Emergency Management Agency (1999), HAZUS Earthquake loss estimation methodology. Federal Emergency Management Agency, Washington, DC.

Federal Emergency Management Agency (2003a), HAZUS-MH MR3 Technical Manual, Washington, DC.

Federal Emergency Management Agency (2003b), ATC-13-1, Report: Commentary on the Use of ATC-13 Earthquake Damage Evaluation Data for Probable Maximum Loss Studies of California Buildings, Washington, DC.

Gallipoli MR, Mucciarelli M, Tket-Motnikar B, Zupancic P, Gosar A, Prevolnik S, Herak M, Stipcevic J, Herak D, Milutinovic Z and Olumceva T (2010), `Empirical estimates of dynamic parameters on a large set of European buildings, _ Bulletin of Earthquake Engineering, 8(3): 593-607.

Gasparini DA and Vanmarcke EH (1976), Simulated earthquake motions compatible with prescribed response spectra. MIT Civil Engineering. Research Report R76-4. Massachussets Institute of Technology.

GNDT (1986). Instruzioni per la Compilazione de lla Sceda di Relivamento Esposizione e Vulnerabilità Sismica Degli Edifici. Gruppo Nazionale per la Difesa dai Terremoti, Regione Emilia Romagna y Regione Toscana, Italy. (in Italian)

Gueguen P, Michel C and LeCorre L (2007), 'A simplified approach for vulnerability assessment in moderate-to-low seismic hazard regions: application to Grenoble (France), _ Bull Earthq. Engng., 4(3), 467-490. DOI: 10.1007/s10518-007-9036-3

Hancock J and Bommer J (2007), 'Using spectral matched records to explore the influence of strong-motion duration on inelastic structural response, . Soil Dynamics and Earthquake Engineering, 27(4): 291-299.

Hans S (2002), ‘uscultation dynamique de bâtiments et modélisation par homogéneisation - 
Contribution à lăanalyse de la vulnerabilité sismique , $\mathrm{PhD}$ thesis, INSA Lyon. (in French).

Hans S, Boutin C, Ibraim E and Roussillon P (2005), 'In situ experiments and seismic analysis of existing buildings. Part I: Experimental investigations, _Earthquake Engineering and Structural Dynamics, 34(12):1513-1529.

Housner GW (1952), 'Intensity of ground motion during strong earthquakes,__Proceedings of the Symposium on Earthquake and Blast Effects on Structures, Earthquake Engineering Research Institute, Berkeley, CA.

Jackson J (2006), 'Fatal attraction: living with earthquakes, the growth of villages into megacities, and earthquake vulnerability in the modern world,_. Philosophical transactions of the royal society A - Mathematical physical and engineering sciences, 364(1845): 1911-1925.

JICA (2007). Technical Cooperation Project, Reduction of Seismic Risk for Buildings and Structures with Romania, 2002-2007.

Kappos AJ, Panagopoulos G, Panagiotopoulos C and Penelis G (2006), 'A hybrid method for the vulnerability assessment of R/C and URM buildings, _ Bulletin of Earthquake Engineering, 4(4): 391-413.

McGuire RK (2004), `Seismic hazard and risk analysis_, Monograph MNO-10, Earthquake Engineering Research Institute (EERI).

Meli R, Faccioli E, Muria-Vila D, Quaas R, and Paolucci R (1998), 'A study of site effects and seismic response of an instrumented building in Mexico City, Journal of Earthquake Engineering, 2(1): $89^{-} 111$.

Michel C, Hans S, Gueguen P and Boutin C (2006), 'In situ experiment and modelling of RCstructure using ambient vibration and Timoshenko beam, _ Proceedings of the First European Conference on Earthquake Engineering and Seismology, Geneva, Switzerland, Paper 1246.

Michel C, Gueguen P and Bard PY (2008), 'Dynamic parameters of structures extracted from ambient vibration measurements: an aid for the seismic vulnerability assessment of existing buildings in moderate seismic hazard regions, _. Soil Dynamics and Earthquake Engineering, 28(8): 593-604.

Michel C, Gueguen P, El Arem S, Mazars J and Kotronis P (2010a), `Full-scale dynamic response of an RC building under weak seismic motions using earthquake recordings, ambient vibrations and modelling, _Earthquake Engineering and Structural Dynamics, 39(4): 419-441.

Michel C, Gueguen P, Lestuzzi P and Bard PY (2010b), `Comparison between seismic vulnerability models and experimental dynamic properties of existing buildings in France,_ Bulletin of Earthquake Engineering, 8(6):1295-1307, DOI : 10.1007/s10518-010-9185-7

Michel C, Gueguen P, and Causse M (2012), 'Seismic vulnerability assessment to slight damage based on experimental modal parameters, _ Earthquake Engineering and Structural Dynamics, 41(1): 81-98 DOI: $10.1002 /$ eqe.1119

Mikael A, Gueguen P, Bard P-Y Roux P, and Langlais M (2013), 'Long-term frequency and damping wandering in buildings analysed using the Random Decrement Technique (RDT)_, Bulletin of Seismological Society of America, 103(1): 236-246 DOI 10.1785/0120120048

Milutinovic ZV and Trendafiloski GS (2003), 'Risk-UE: an advanced approach to earthquake risk scenarios with applications to different European towns, WP4: vulnerability of current buildings. European Project.

Mironescu M, Stanescu A, Brotea T, Bortnowski A, Sava V and Comanescu R (2003), 'Modeling, configuration and analysis for high importance buildings, _ Bulletin of the Association of Structural Design Engineers AICPS, Bucharest, 3: 1-17. (In Romania)

Nayeri RD, Masri SF, Ghanem RG and Nigbor RL (2008), 'A novel approach for the structural identification and monitoring of a full-scale 17-story building based on ambient vibration measurements,_Smart Materials and Structures, 17(2): 19p.

Onose JI (1982), 'Prediction of damage ratio of reinforced concrete buildings due to earthquakes and comparison with actual damage ratio, Proceedings of the $6^{\text {th }}$ Japan Earthquake Engineering Symposium: Japan Society of Civil Engineers, Tokyo, 2081-2088.

Orsini G (1999), 'A model for buildings vulnerability assessment using the parameterless scale of 
seismic intensity (PSI),_Earthquake Spectra, 15(3): 463-483.

Péquegnat C, Gueguen P, Hatzfeld D and Langlais M (2008), 'The French Accelerometric Network (RAP) and National Data Centre (RAP-NDC),_Seismological Research Letters, 79(1): 79-89.

Perrault M and Gueguen P (2010), 'Evaluation of the seismic damage with the use of experimental and theoretical models, _ Proceedings of the $14^{\text {th }}$ European Conference on Earthquake Engineering, Ohrid, Macedonia, Paper 871.

Pierre JP and Montagne M (2004), 'The 20 April 2002, Mw 5.0 Au Sable Forks, New York, earthquake : a supplementary source of knowledge on earthquake damage to lifelines and buildings in Eastern North America,_Seismol Res Lett, 75(5):626-635

Pinho R, Bommer JJ and Glaister S (2002), 'A simplified approach to displacement-based earthquake loss estimation analysis, . Proceedings of the 12th European Conference on Earthquake Engineering, London, England, Paper 738.

Risk-UE (2003), `An advanced approach to earthquake risk scenarios with applications to different European towns. WP4: Vulnerability of current buildings,_European Project.

Rossetto T and Elnashai A (2003), 'Derivation of vulnerability functions for European-type RC structures based on observational data,_Engineering Structures, 25(10): 1241-1263.

Seyedi M, Gehl P, Douglas J, Davenne L, Mehzer N and Ghavamian S (2010), 'Development of seismic fragility surfaces for reinforced concrete buildings by means of nonlinear time-history analysis, _Earthquake Engineering and Structural Dynamics, 39(1): 91-108.

Singhal A and Kiremidjian AS (1997), 'A method for earthquake motion-damage relationships with application to reinforced concrete frames, _. State University of New York at Buffalo: National Center for Earthquake Engineering Research (Report NCEER-97-0008).

Spence RJS, Bommer J, Del Re D, Bird J, Aydinoglu N and Tabuchi S (2003), 'Comparison Loss Estimation with Ob- served Damage: A study of the 1999 Kocaceli Earthquake in Turkey,. Bulletin of Earthquake Engineering, 1: 83-113.

Spence RJS, Coburn AW and Pomonis A (1992), 'Correlation of ground motion with building damage: the definition of a new damage-based seismic intensity scale,_ $10^{\text {th }}$ World Conference of Earthquake Engineering, Rotterdam, 551-556.

Todorovska MI and Trifunac MD (2007), 'Damage detection in the Imperial County Services Building. I: the data and time ${ }^{-}$frequency analysis, . Soil Dynamics and Earthquake Engineering, 27: $564^{-} 576$.

Trifunac MD (1972), 'Comparison between ambient and forced vibration experiments. Earthquake Engineering and Structural Dynamics, 1 (1); 33-150.

Turek M, Thibert K, Ventura C and Kuan S (2006), 'Ambient vibration testing of three unreinforced brick masonry buildings in Vancouver, Canada, _ Proceedings of the $24^{\text {th }}$ International Modal Analysis Conference (IMAC), Saint Louis, MI, USA.

Ventura CE, Liam Finn WD and Schuster ND (1995), `Seismic Response of Instrumented Structures During the 1994 Northridge California Earthquake,_ Canadian Journal of Civil Engineering, 22: 316-337.

Ventura CE and Ding Y (2000), 'Linear and nonlinear seismic response of a 52-storey steel frame building, _ Structural Design of Tall Buildings, 9(1): 25-45.

Volant P, Orbovic N and Dunand F (2002), `Seismic evaluation of existing nuclear facility using ambient vibration test to characterize dynamic behavior of the structure and microtremor measurements to characterize the soil: a case study, Soil Dynamics and Earthquake Engineering, 22:1159-1167.

Wald DJ, Quitoriano V, Heaton T and Kanamori H (1999), `Relationships between peak ground acceleration, peak ground velocity, and modified Mercalli intensity in California _, Earthquake Spectra, 15 (3): $557^{-} 564$. 



\begin{tabular}{|c|c|c|c|c|c|c|c|c|c|c|c|c|c|}
\hline \# & Date & $\mathrm{M}_{\mathrm{W}}$ & $\begin{array}{c}\text { Epicentral } \\
\text { distance } \\
(\mathrm{km})\end{array}$ & $\begin{array}{l}\text { Focal } \\
\text { depth } \\
(\mathrm{km}) \\
\end{array}$ & $\begin{array}{l}\text { PGA } \\
\left(\mathrm{cm} / \mathrm{s}^{2}\right)\end{array}$ & $\begin{array}{c}\text { PTA } \\
\left(\mathrm{cm} / \mathrm{s}^{2}\right)\end{array}$ & $\begin{array}{l}\text { PGV } \\
(\mathrm{cm} / \mathrm{s})\end{array}$ & $\begin{array}{c}\text { PTV } \\
(\mathrm{cm} / \mathrm{s})\end{array}$ & $\begin{array}{l}\text { PGD } \\
(\mathrm{mm})\end{array}$ & $\begin{array}{l}\text { PTD } \\
(\mathrm{mm})\end{array}$ & $\begin{array}{c}\mathrm{Ia} \\
(\mathrm{cm} / \mathrm{s})\end{array}$ & $\begin{array}{l}\text { CAV } \\
(\mathrm{cm} / \mathrm{s})\end{array}$ & $\begin{array}{l}\text { Drift } \\
(\mathrm{mm})\end{array}$ \\
\hline 1 & 21/01/2004 & 4.1 & 130 & 118 & 1.31 & 3.04 & 0.04 & 0.12 & 0.04 & 0.27 & 0.05 & 1.87 & 0.18 \\
\hline 2 & |07/02/2004 & 4.4 & 148 & 146 & 0.91 & 2.74 & 0.03 & 0.11 & 0.03 & 0.29 & 0.02 & 1.60 & 0.26 \\
\hline 3 & \begin{tabular}{|l|}
$10 / 07 / 2004$ \\
\end{tabular} & 4.3 & 123 & 150 & 1.60 & 2.79 & 0.07 & 0.15 & 0.05 & 0.16 & 0.08 & 2.37 & 0.14 \\
\hline 4 & 27/09/2004 & 4.6 & 139 & 166 & 4.94 & 2.17 & 0.35 & 0.76 & 0.29 & 0.81 & 1.33 & 8.71 & 0.79 \\
\hline 5 & 27/10/2004 & 6.0 & 163 & 99 & 36.85 & 69.43 & 2.25 & 5.24 & 2.31 & 5.28 & 68.32 & 99.36 & 4.92 \\
\hline 6 & |17/11/2004 & 4.4 & 152 & 127 & 0.78 & 2.09 & 0.03 & 0.09 & 0.04 & 0.29 & 0.02 & 1.44 & 0.34 \\
\hline 7 & \begin{tabular}{|l|}
$14 / 05 / 2005$ \\
\end{tabular} & 5.2 & 139 & 144 & 5.06 & \begin{tabular}{|l|}
14.73 \\
\end{tabular} & 0.31 & 0.97 & 0.41 & 1.36 & 1.13 & 9.70 & 1.24 \\
\hline 8 & \begin{tabular}{|l|}
$18 / 06 / 2005$ \\
\end{tabular} & 5.0 & 162 & 135 & 6.03 & 15.70 & 0.30 & 1.02 & 0.30 & 0.83 & 1.27 & 8.74 & 0.87 \\
\hline 9 & |08/09/2005 & 4.3 & 121 & 140 & 0.76 & 1.42 & 0.04 & 0.08 & 0.04 & 0.16 & 0.03 & 1.57 & 0.14 \\
\hline 10 & 13/12/2005 & 4.8 & 158 & 144 & 7.67 & 28.00 & 0.31 & 1.11 & 0.25 & 0.91 & 1.86 & 10.55 & 0.94 \\
\hline 11 & \begin{tabular}{|l|}
$18 / 12 / 2005$ \\
\end{tabular} & 3.7 & 107 & 60 & 1.08 & 3.39 & 0.03 & 0.11 & 0.02 & 0.12 & 0.06 & 2.16 & 0.13 \\
\hline 12 & \begin{tabular}{|l|}
$16 / 02 / 2006$ \\
\end{tabular} & 4.1 & 147 & 130 & 0.88 & 2.10 & 0.02 & 0.08 & 0.02 & 0.09 & 0.02 & 1.14 & 0.10 \\
\hline 13 & 06/03/2006 & 4.8 & 142 & 145 & 1.00 & 3.47 & 0.06 & 0.19 & 0.05 & 0.84 & 0.07 & 2.77 & 0.58 \\
\hline 14 & 23/09/2006 & 4.3 & 124 & 131 & 0.67 & 2.05 & 0.03 & 0.09 & 0.03 & 0.16 & 0.02 & 1.23 & 0.11 \\
\hline 15 & \begin{tabular}{|l|}
$17 / 01 / 2007$ \\
\end{tabular} & 4.3 & 126 & 120 & 2.24 & 4.68 & 0.08 & 0.19 & 0.06 & 0.13 & 0.11 & 2.24 & 0.16 \\
\hline 16 & \begin{tabular}{|l|}
$14 / 02 / 2007$ \\
\end{tabular} & 4.2 & 121 & 159 & 0.83 & 1.54 & 0.03 & 0.08 & 0.04 & 0.12 & 0.02 & 1.34 & 0.14 \\
\hline 17 & \begin{tabular}{|l|}
$11 / 02 / 2008$ \\
\end{tabular} & 4.0 & 132 & 100 & 1.46 & 3.39 & 0.04 & 0.11 & 0.02 & 0.07 & 0.03 & 1.34 & 0.06 \\
\hline 18 & \begin{tabular}{|l|}
$25 / 04 / 2009$ \\
\end{tabular} & 6.0 & 143 & 101 & 13.24 & 37.50 & 0.55 & 2.30 & 1.06 & 3.30 & 6.94 & 21.99 & 3.22 \\
\hline 19 & \begin{tabular}{|l|}
$27 / 05 / 2009$ \\
\end{tabular} & 4.4 & 139 & 145 & 1.87 & 4.60 & 0.05 & 0.18 & 0.05 & 0.14 & 0.07 & 2.23 & 0.10 \\
\hline 20 & 20/06/2009 & 3.7 & 43 & 14 & 0.62 & 1.63 & 0.03 & 0.09 & 0.03 & 0.22 & 0.02 & 1.56 & 0.22 \\
\hline 21 & \begin{tabular}{|l|}
$05 / 08 / 2009$ \\
\end{tabular} & 5.5 & 243 & 1 & 1.42 & 4.60 & 0.12 & 0.44 & 0.24 & 0.67 & 0.65 & 10.81 & 0.58 \\
\hline 22 & 22/10/2009 & 3.7 & 140 & 157 & 0.59 & 1.32 & 0.03 & 0.06 & 0.03 & 0.25 & 0.02 & 1.11 & 0.24 \\
\hline 23 & 26/12/2009 & 4.0 & 153 & 102 & 2.07 & 4.84 & 0.05 & 0.12 & 0.02 & 0.17 & 0.08 & 2.01 & 0.19 \\
\hline 24 & $25 / 02 / 2010$ & 3.7 & 133 & 105 & 1.15 & 2.15 & 0.03 & 0.07 & 0.04 & 0.28 & 0.02 & 1.36 & 0.29 \\
\hline 25 & $08 / 06 / 2010$ & 4.5 & 130 & 113 & 3.54 & 7.54 & 0.13 & 0.34 & 0.09 & 0.18 & 0.28 & 3.70 & 0.21 \\
\hline
\end{tabular}

Table 1. Description of the events recorded in the BRD Tower between 2004 and 2010. Magnitude, localization (i.e. epicentral distances) and focal depths are provided by the Romanian National Institute for Earth Physics (NIEP). The peak ground acceleration (PGA), the peak ground velocity (PGV), the peak ground displacement (PGD), the Arias intensity (Ia) and the cumulative absolute velocity $(\mathrm{CAV}$, computed without any threshold) are computed from the records at the bottom of the BRD Tower; the peak top acceleration (PTA), the peak top velocity (PTV) and the peak top displacement (PTD) from the records at the top; the drift is computed as the maximal relative. 


\begin{tabular}{|c|c|c|c|c|}
\cline { 2 - 4 } \multicolumn{1}{c|}{} & \multicolumn{2}{|c|}{ Transversal direction } & \multicolumn{2}{c|}{ Longitudinal direction } \\
\cline { 2 - 5 } & $\mathrm{f}_{1}(\mathrm{~Hz})$ & $\mathrm{f}_{2}(\mathrm{~Hz})$ & $\mathrm{f}_{1}(\mathrm{~Hz})$ & $\mathrm{f}_{2}(\mathrm{~Hz})$ \\
\hline Set $1-\mathrm{PGA}<3.5 \mathrm{~cm} / \mathrm{s} 2$ & 1.11 & 4.57 & 1.48 & 5.82 \\
\hline Set $2-\mathrm{PGA}>3.5 \mathrm{~cm} / \mathrm{s} 2$ & 1.09 & 4.41 & 1.50 & 5.81 \\
\hline Set $3{ }^{-} 10 / 27 / 2004$ earthquake & 1.07 & 4.42 & 1.50 & 5.87 \\
\hline
\end{tabular}

Table 2. Experimental frequencies of the BRD Tower evaluated by applying Frequency Domain Decomposition on the three sets of earthquakes. 


\begin{tabular}{|c|c|c|c|c|c|c|c|c|}
\cline { 2 - 6 } \multicolumn{1}{c|}{} & \multicolumn{4}{c|}{ Frequencies (Hz) } & \multicolumn{4}{c|}{ Damping (\%) } \\
\hline \multirow{2}{*}{ Nayeri et al. (2008) } & $\mu\left(\mathrm{f}_{1}\right)$ & 1.11 & $\sigma\left(\mathrm{f}_{1}\right)$ & 0.006 & $\mu(\zeta)$ & 1.00 & $\sigma(\zeta)$ & 2.015 \\
\cline { 2 - 10 } & $\mu\left(\mathrm{f}_{2}\right)$ & 4.56 & $\sigma\left(\mathrm{f}_{2}\right)$ & 0.020 & & \\
\hline \multirow{3}{*}{ Mikael et al. (2013) } & $\mu\left(\mathrm{f}_{1}\right)$ & 1.11 & $\sigma\left(\mathrm{f}_{1}\right)$ & 0.007 & & \multirow{2}{*}{1.00} & $\sigma(\zeta)$ & 0.158 \\
\cline { 2 - 10 } & $\mu\left(\mathrm{f}_{2}\right)$ & 4.56 & $\sigma\left(\mathrm{f}_{2}\right)$ & 0.020 & $\mu(\zeta)$ & & \\
\hline
\end{tabular}

Table 3. Mean values and standard deviations of the lognormal distributions of frequencies and damping, following the values provided by the studies of Nayeri et al. (2008) and Mikael et al. (2013). For a distribution of frequencies, the damping remains constant ( $\zeta=1 \%$ for each mode); respectively, for a distribution of damping, the modal frequencies $f_{1}$ and $f_{2}$ remain constant $\left(\mathrm{f}_{1}=1.11 \mathrm{~Hz} ; \mathrm{f}_{2}=4.56 \mathrm{~Hz}\right)$ and the damping are considered as the same for each mode $\left(\zeta_{1}=\right.$ $\left.\zeta_{2}=\zeta_{3}=\zeta_{4}=\zeta_{5}\right)$. 


\section{FIGURE CAPTIONS}

Figure 1. BRD instrumented building - headquarters of BRD - Société Générale Bank in Romania.

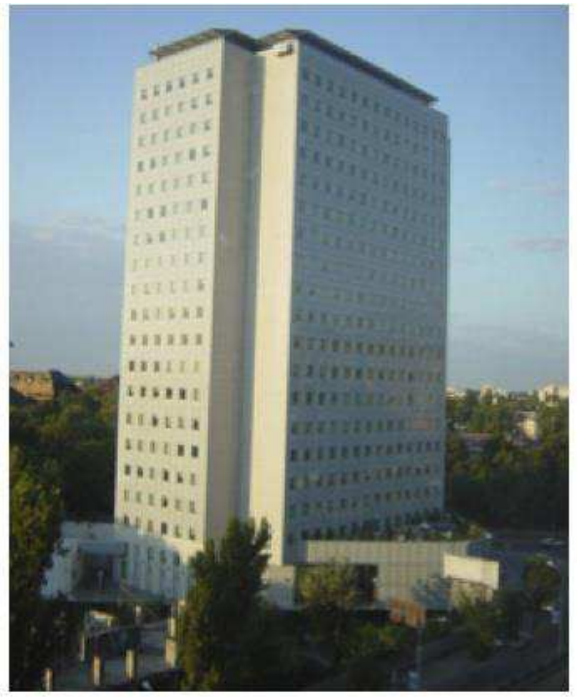

Figure 2. Ratios $\mathrm{f}_{\mathrm{k}} / \mathrm{f}_{1}$ according to the value of $\mathrm{C}$ considering a Timoshenko beam model.

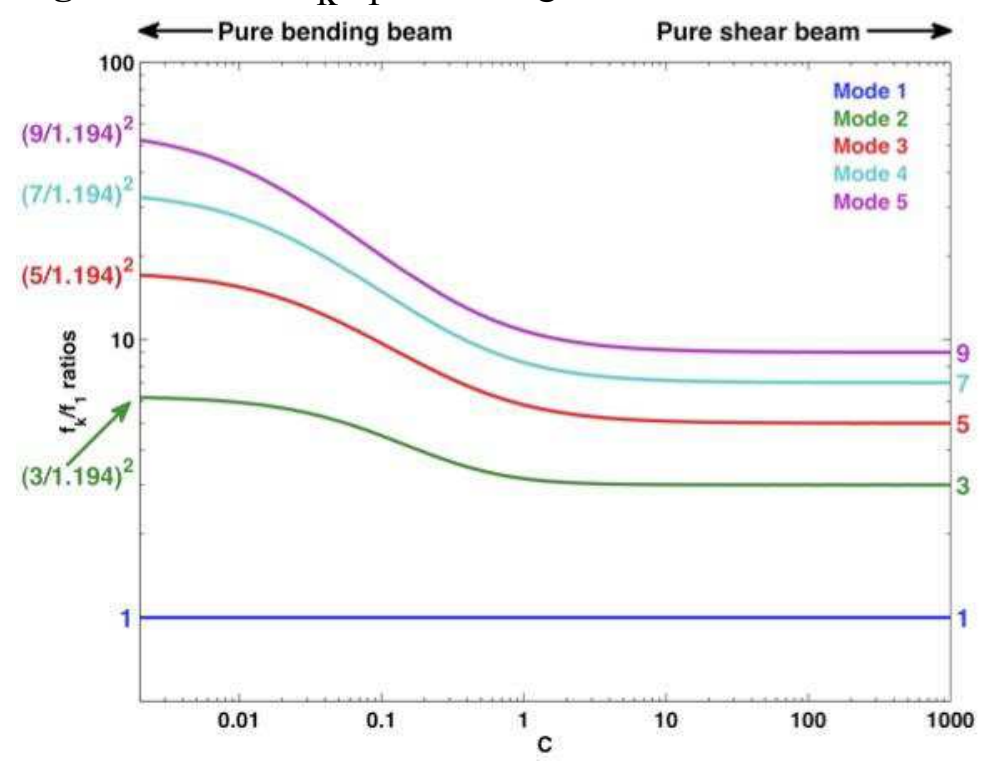


Figure 3. The three first mode shapes of the Timoshenko model (black lines) corresponding to the BRD-Tower, in the transversal direction (left), for which we obtained $\mathrm{C}_{\mathrm{T}}=0.159$, and the longitudinal direction (right), for which we obtained $C_{L}=0.195$. The mode shapes of the pure bending beam and the pure shear beam are also plotted (red and blue lines, respectively). The mode shapes of both $\mathrm{T}$ and $\mathrm{L}$ Timoshenko models are very similar to each other because the $\mathrm{C}$ values are very close.
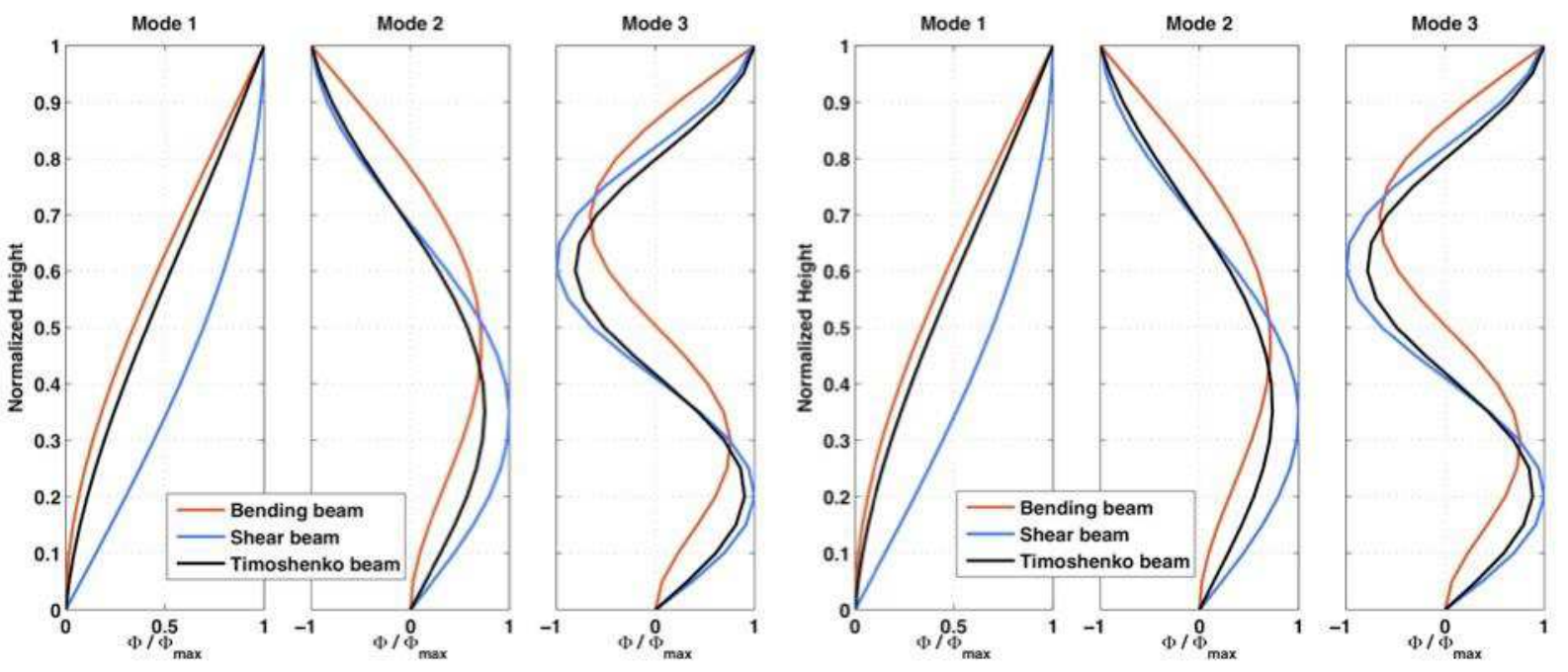

Figure 4. Example of the $27 / 10 / 04$ earthquake $\left(\mathrm{M}_{\mathrm{W}}=6.0\right)$, in the transverse direction of the structure. Comparison between observation and simulation at the top of the BRD Tower (left) and Anderson $\breve{s}$ criteria representation (right): the scores of each frequency band are represented by a thin line and the thick line shows the averaged score. Each value corresponds to an Anderson criterion: $\mathrm{S}_{\mathrm{Da}}$ : Arias duration, $\mathrm{S}_{\mathrm{De}}$ : Energy duration, $\mathrm{S}_{\mathrm{Ia}}$ : Arias intensity, $\mathrm{S}_{\mathrm{IV}}$ : Energy integral, $\mathrm{S}_{\mathrm{PGA}}$ : Peak acceleration, $\mathrm{S}_{\mathrm{PGV}}$ : Peak velocity, $\mathrm{S}_{\mathrm{PGD}}$ : Peak displacement, $\mathrm{S}_{\mathrm{SA}}$ : Response spectra, $\mathrm{S}_{\mathrm{Fs}}$ : Fourier spectra and $\mathrm{C}^{*}$ : Cross correlation.
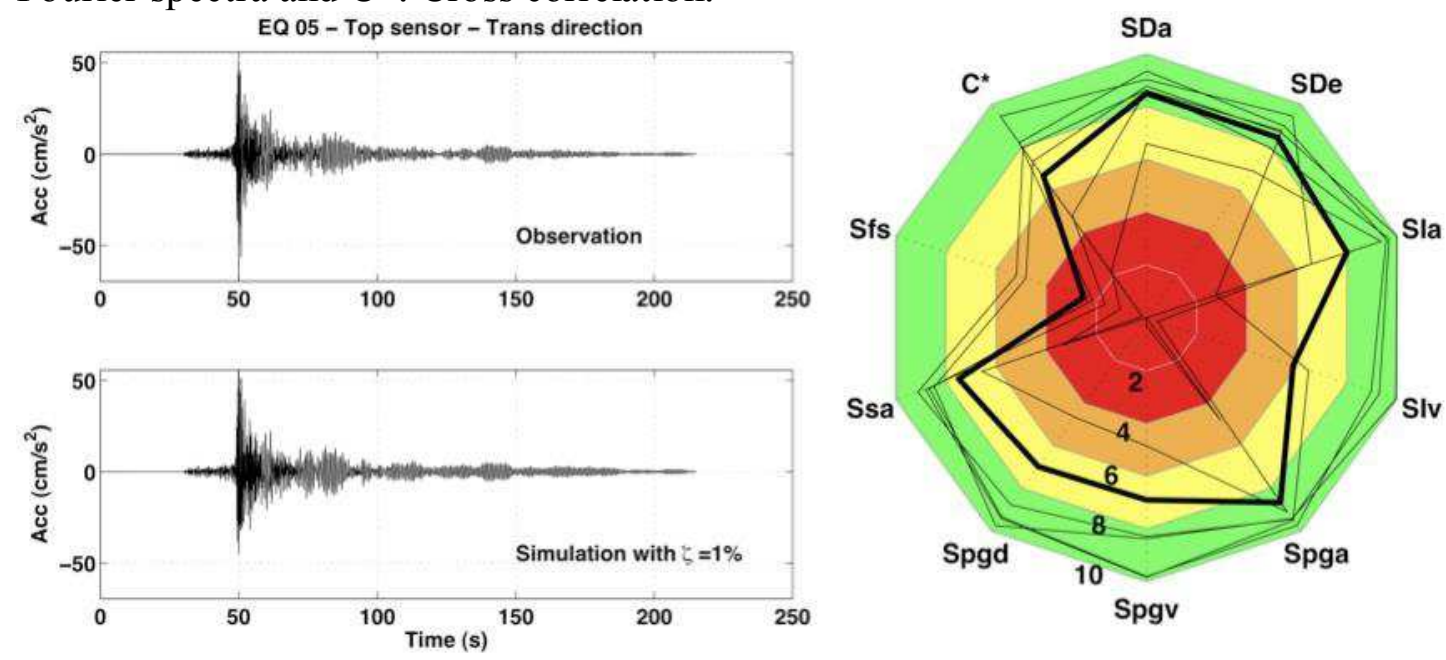
Figure 5. Similarity between recorded and synthetic accelerations at the top of the BRD Tower in the transversal (two left columns) and longitudinal (two right columns) directions, considering the damping values providing the best Anderson $\breve{s}$ criteria values $(0.5,1,2$ and $3 \%$ for the $\mathrm{T}$ direction and 3, 4, 5 and $6 \%$ for the $\mathrm{L}$ direction) A) represented for each Anderson $\breve{s}$ criteria (the thin polygons correspond to the values of the Anderson $\breve{s}$ criteria averaged over the six frequency bands, i.e. [0.5 1.0], [1.0 2.0], [2.0 5.0], [5.0 10.0], [1 10.0 20.0] and [0.5 20.0] Hz, for each of the 25 earthquakes recorded between 2004 and 2010, see Tab 1) ${ }^{-}$B) represented for the six frequency bands (the thin polygons correspond to the mean values obtained from the 10 Anderson $\breve{s}$ criteria, for each of the 25 earthquakes recorded between 2004 and 2010). The thick polygon corresponds to the average on the 25 earthquakes.

A)
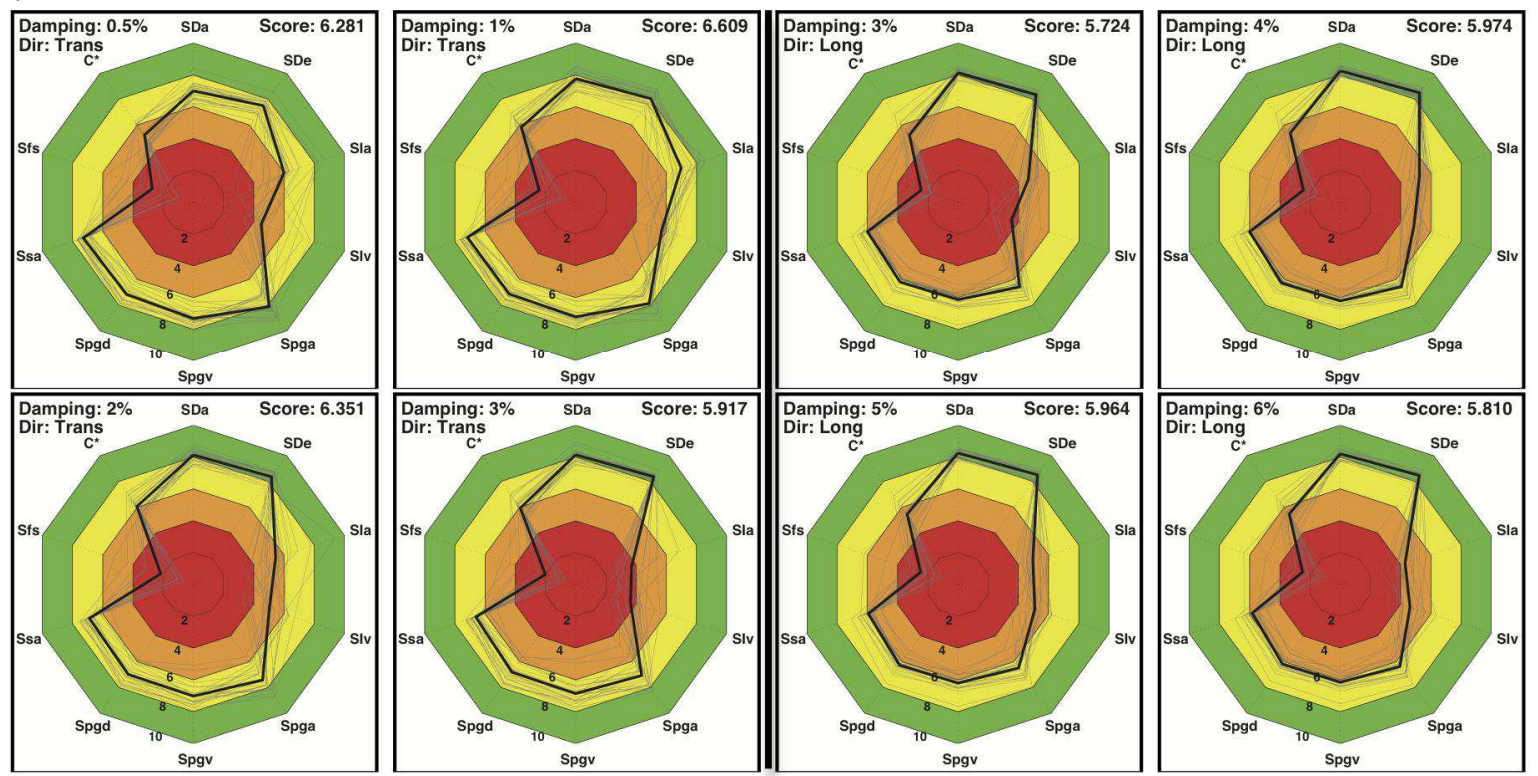

B)
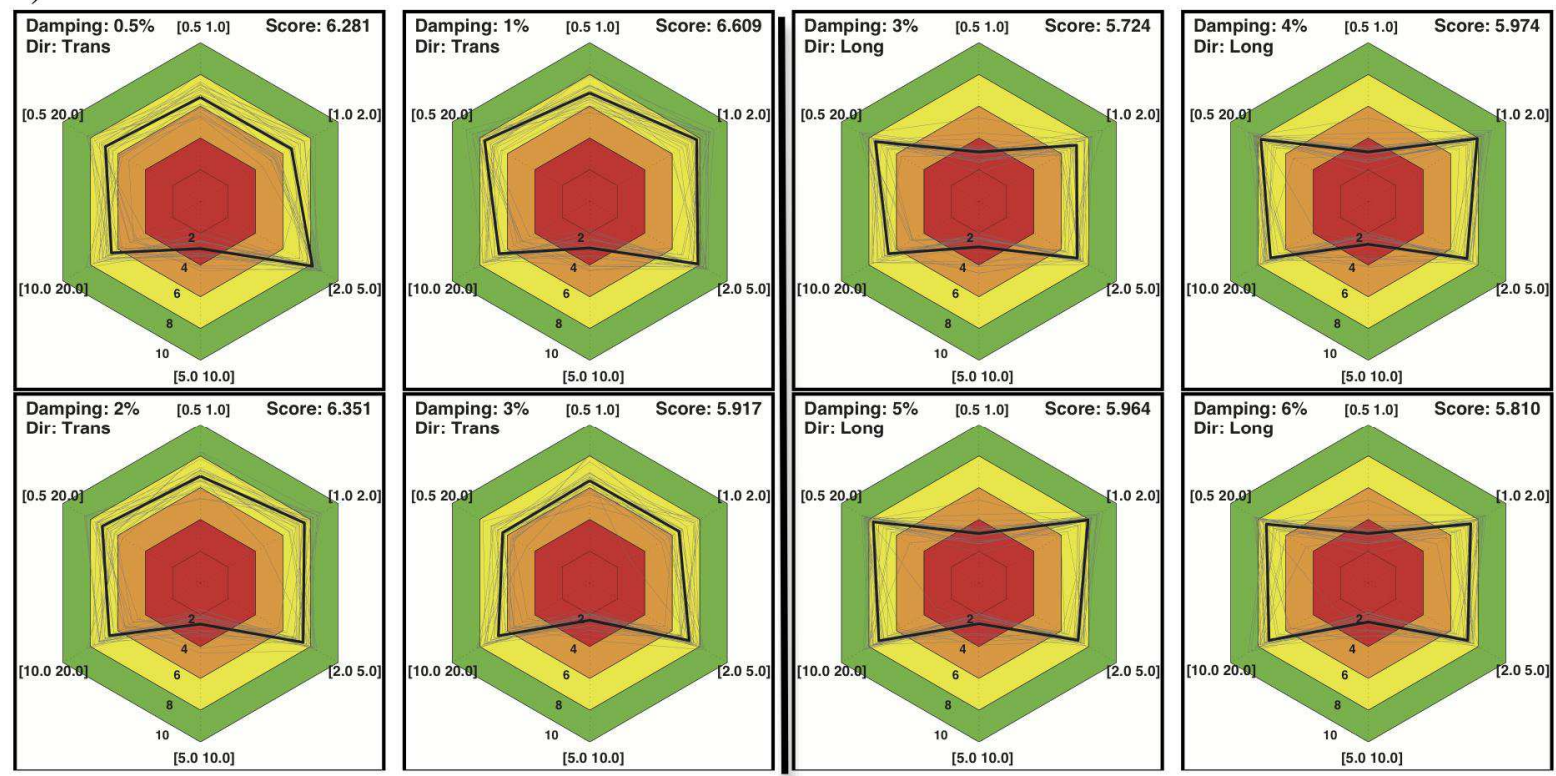
Figure 6. Fragility curves for the BRD Tower, plotted from various IM: from top to bottom and from left to right, spectral displacement, spectral velocity and spectral acceleration taken at the first and second modal frequencies of the building, peak ground acceleration, peak ground velocity, peak ground displacement, Arias intensity, Housner intensity and Cumulative Absolute Velocity. The fragility curves are given only for the slight damage state.
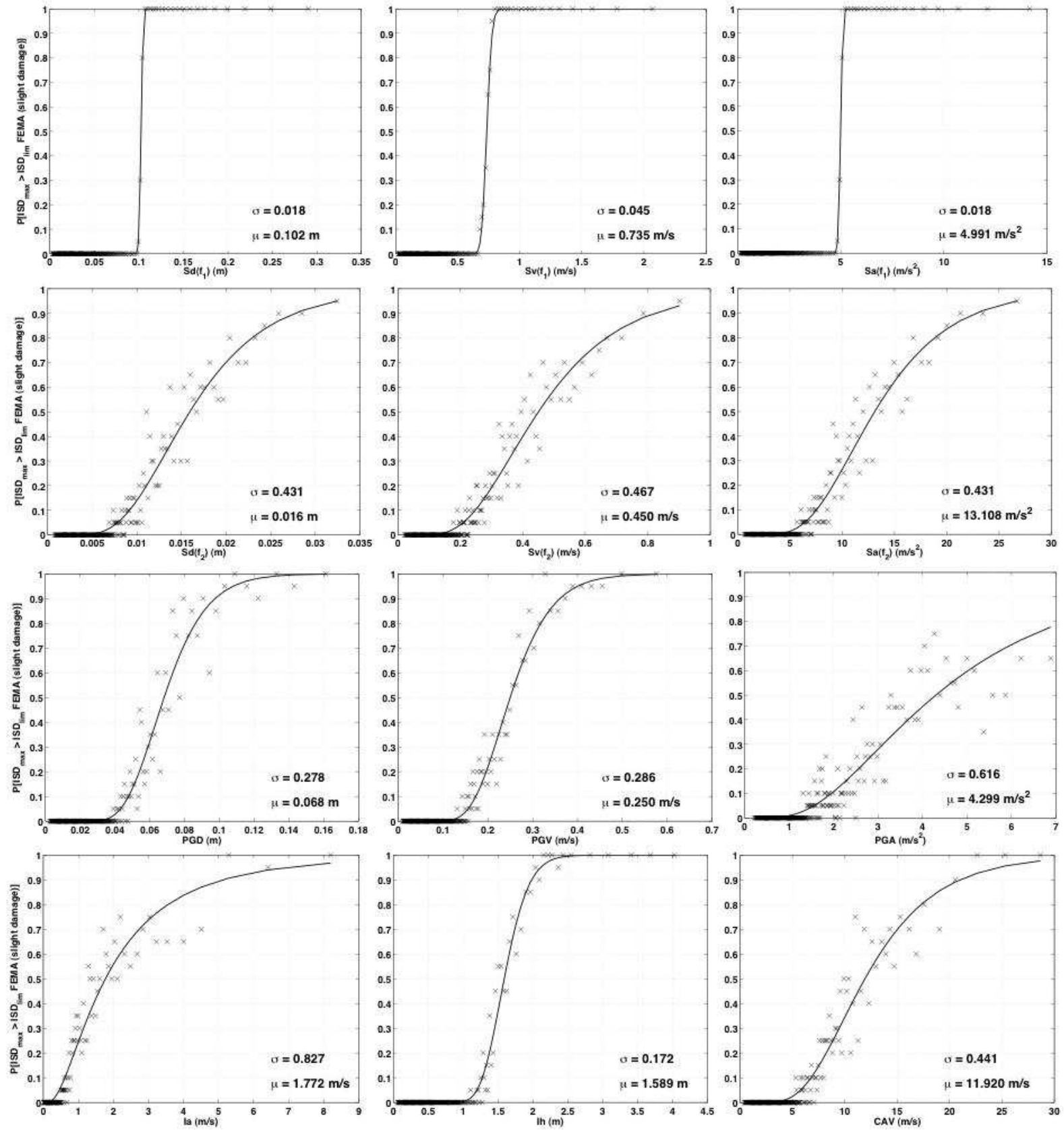
Figure 7. Distribution of the fragility curves, from distributions of frequencies $f_{1}$ and $f_{2}$ provided by: left: Nayeri et al. (2008); right: Mikael et al. (2013). The thin curves represent the fragility curves relative to the 100 models we used from the distributions. The thick curve corresponds to the median curve, and the dashed curves to the median \pm standard deviation. The fragility curves are given only for the slight damage state.
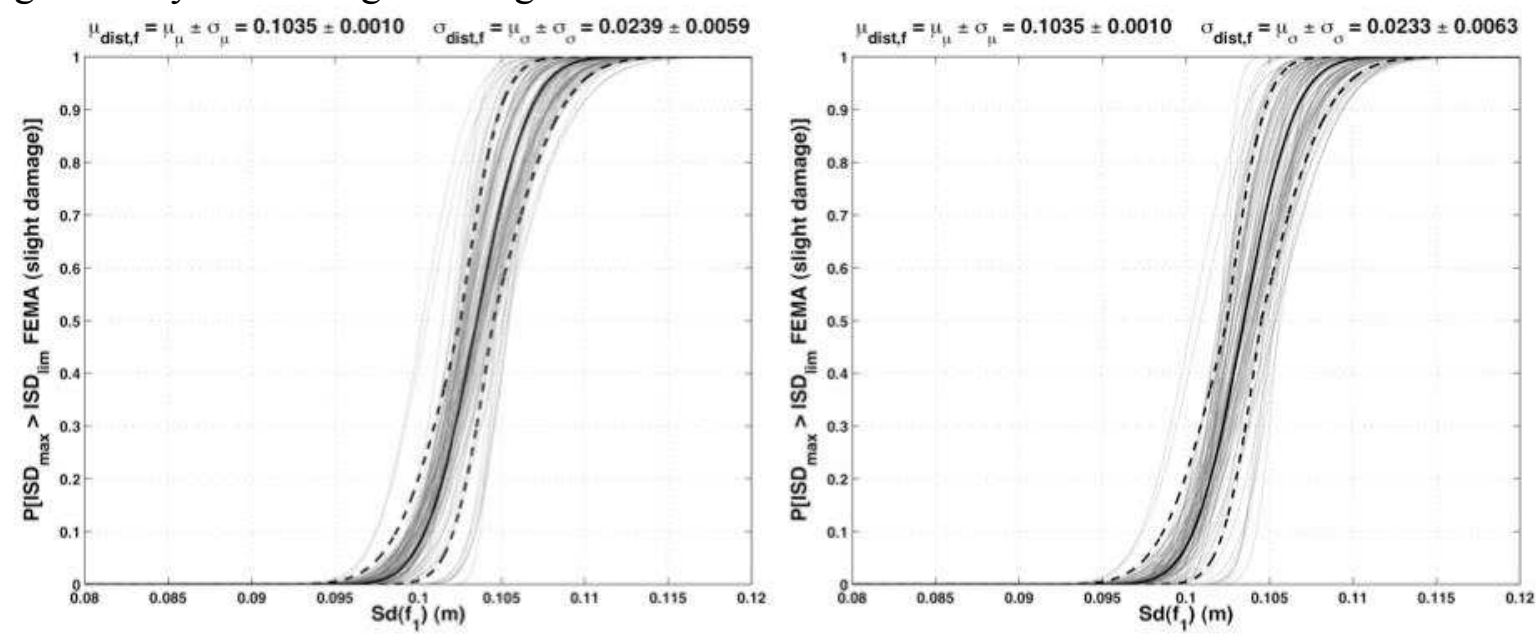

Figure 8. Distribution of the fragility curves, from distributions of damping provided by: left: Nayeri et al. (2008); right: Mikael et al. (2013). The thin curves represent the fragility curves relative to the 100 models we used from the distributions. The thick curve corresponds to the median curve, and the dashed curves to the median \pm standard deviation. The fragility curves are given only for the slight damage state.
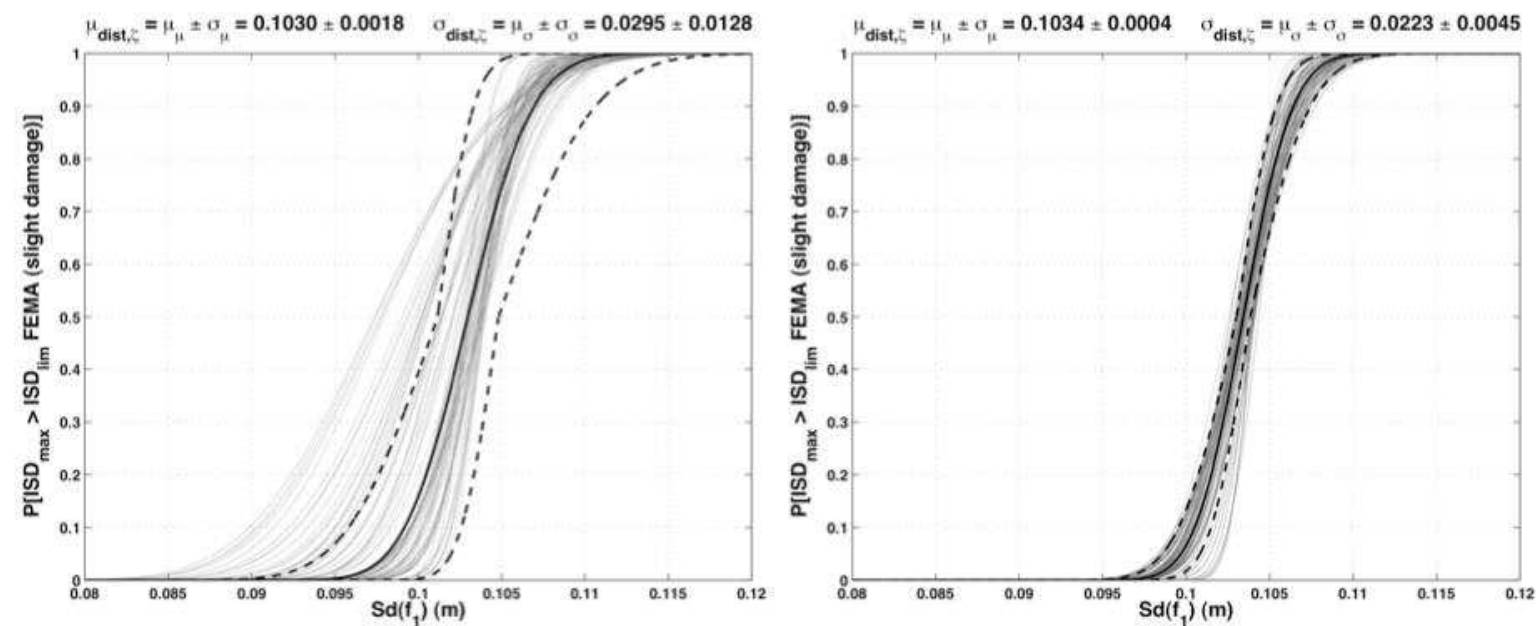
Figure 9. Fragility curves of the BRD Tower, in its transversal (red) and longitudinal (blue) directions. Two curves are presented for each direction, corresponding to the two types of construction that we considered for the building: $\mathrm{C} 1 \mathrm{H}$ (dashed lines), corresponding to a concrete moment frame structure, and $\mathrm{C} 2 \mathrm{H}$ (continuous lines), corresponding to a concrete shear wall structure, as defined by FEMA (2003a). The black curves are the Hazus fragility curves provided by the FEMA for the two types of structure. The gray area corresponds to the surface located between both extreme $\mathrm{C} 1 \mathrm{H}$ and $\mathrm{C} 2 \mathrm{H}$ curves, and is expected to contain the intermediate fragility curve associated with the BRD Tower.

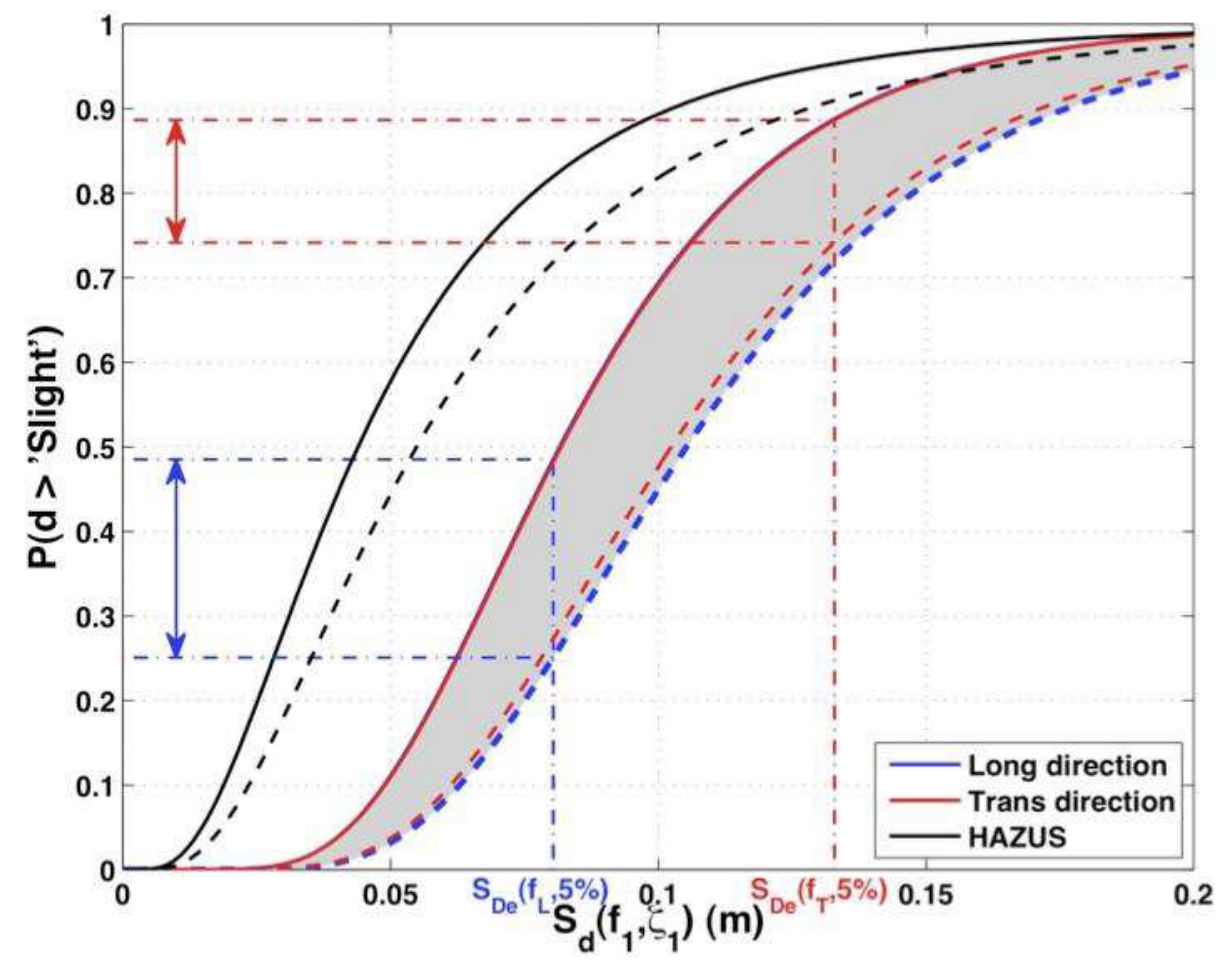

Figure 10. Displacement elastic response spectrum for the Bucharest area, according to P100$1 / 2006$ Romanian seismic design code. In blue and red are represented the values of the elastic response spectrum in the transversal and longitudinal frequencies of the BRD Tower.

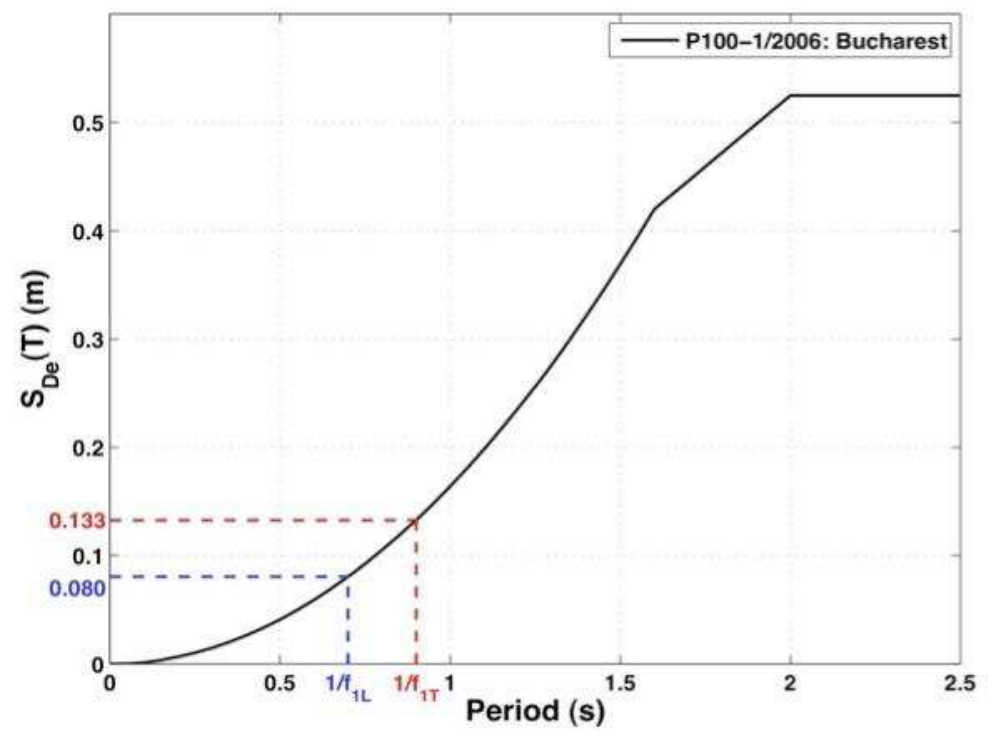


